\title{
Capture of harmful radioactive contaminants from off-gas stream using porous solid sorbents for clean environment - A review
}

Sachin U. Nandanwar ${ }^{\mathrm{a}}$, Kai Coldsnow ${ }^{\mathrm{a}}$, Vivek Utgikar ${ }^{\mathrm{a},{ }^{*}}$, Piyush Sabharwall $^{\mathrm{b}}$, D. Eric Aston ${ }^{\mathrm{a}}$

${ }^{a}$ Department of Chemical and Materials Engineering, University of Idaho, Moscow, Idaho 83844-1021, United States

${ }^{b}$ Idaho National Laboratory, Idaho Falls, Idaho 83415, United States

\begin{abstract}
Nuclear energy production is growing rapidly worldwide to satisfy increasing energy demands. Reprocessing of used nuclear fuel (UNF) is expected to play an important role for sustainable development of nuclear energy by increasing the energy extracted from the fuel and reducing the generation of the high level waste (HLW). However, during the reprocessing of Used Nuclear Fuel (UNF) gaseous radioactive nuclides including iodine, krypton, xenon, carbon, and tritium are released into the atmosphere through off-gas streams. The volatile iodine $\left({ }^{129} \mathrm{I}\right)$, and krypton $\left({ }^{85} \mathrm{Kr}\right)$ gases have long lived-isotopes; which have adverse effects on the environment as well as human health. Consequently, the capture of these two target radionuclides (species) is essential for the enhanced growth of nuclear energy. In this review we discuss several techniques for capture of volatile contaminants iodine, krypton, and xenon, focusing upon adsorption using solid sorbents, which has shown promising results for more than 70 years. Commonly used and recently developed sorbents are summarized in this article along with a short review of the results. Metal-organicframeworks (MOFs), gaining favor in recent years as sorbents for the capture of off-gas contaminants are also discussed. Finally, some considerations of future trends and prospects for investigations of the capture of volatile radionuclides are presented.
\end{abstract}

Keywords: Off-gas stream, Volatile contaminants, Environment, Adsorption, Porous solid sorbents, Removal of gases 
*Corresponding author:

Department of Chemical and Materials Engineering, University of Idaho 875 Perimeter Dr.;

MS 1021; Moscow, ID 83844-1021, USA. Tel.: +1-208-885-6970, Fax: +1-208-885-7462;

Email address: vutgikar@uidaho.edu (V. Utgikar).

\section{Introduction}

The $21^{\text {st }}$ century continues to see an unrelenting increase in energy demand worldwide due to rapid population and industrial growth, resulting in significant strain on the energy supply from the traditional fossil resources. Energy conservation and discovery of alternative primary energy resources are among the most pressing universal challenges to satisfy the current and future energy demands [1]. The U.S. Department of Energy (DOE) forecasts a nearly 28\% increase in demand for electrical energy from 2012 to 2040 [2, 3]. Currently, fossil fuels dominate the primary energy supply accounting for $67 \%$ (coal - 40\%, natural gas $22 \%$ and others) of electricity production [4]. However, the harmful effects of fossil fuels on the environment (and ultimately, human beings) have been well recognized [5, 6], making it imperative to transition to a superior energy source that can satisfy these increasing demands in a way that does not exacerbate the environmental concerns.

Nuclear energy is one of these alternative sources for the production of electrical energy without excessive greenhouse gas emissions. It is safe, efficient, reliable and an inexpensive source of energy [7]. More than 400 nuclear reactors in 31 countries worldwide produce nearly $11.5 \%$ of global electricity [8]. It is attractive as a major source of electricity generation, as it does not suffer from the same technological and economic limitations as solar or wind energy. The nuclear electricity production is growing steadily to satisfy the worldwide energy demand and is projected to grow between 23 and $100 \%$ by 2030 [9]. However, nuclear energy is faced with the challenge of the management of radioactive waste produced at each stage of the nuclear fuel cycle, which can limit its growth. The radioactive 
wastes are classified as solid (high-level), liquid (low-level), and gases [10]. Gaseous radioactive waste presents an immediate threat to general population and the environment because of the ease of dispersal through the atmosphere.

Only a small fraction of radionuclide emission takes place during nuclear plant operation, primarily from minor leakage from the fuel rods [11]. The majority of radionuclide emissions take places during the aqueous reprocessing of used nuclear fuel (UNF) as it is chopped and dissolved in boiling nitric acid for subsequent extraction steps (PUREX process) [12]. Major gaseous radionuclides released into the atmosphere through off-gas include ${ }^{129} \mathrm{I}$, ${ }^{14} \mathrm{C},{ }^{3} \mathrm{H}$ and noble gases $\left({ }^{85} \mathrm{Kr}\right.$ and multiple Xe isotopes). ${ }^{129} \mathrm{I}$ and ${ }^{85} \mathrm{Kr}$ are a primary concern for the environmental pollution because of their long-lived isotopes that persist and accumulate in the environment [10]. ${ }^{129} \mathrm{I}$ is a highly mobile and volatile contaminant with a half-life of $1.52 \times 10^{7} \mathrm{yr}$, and which bioaccumulates concentrating in the thyroid gland affecting biometabolism [13]. ${ }^{131}$ I is another isotope of iodine, which has low half-life period $8.02 \mathrm{~d}$. The long-lived isotope of Xe has a half-life of $36.4 \mathrm{~d}$ and will yield stable isotopes after typical UNF storage time of about 2 yr. ${ }^{85} \mathrm{Kr}$ is a chemically inert radioisotope with a half-life of $10.7 \mathrm{yr}$ that poses more of a human health and environmental threat as it is continuously accumulated in the atmosphere [14].

Development of methods for the capture and long-term storage of radioactive gases is of crucial importance in order to manage their emissions, that are anticipated to increase significantly with the growth of nuclear energy. Several methods are available for removal of radioactive contaminants from off-gas streams, each with its own advantages and disadvantages. For more than 70 years, porous solid sorbents have been in the forefront of radioactive contaminant removal due to promising results and their advantages such as high removal efficiency, low maintenance cost, simple equipment design and operation over other techniques. Notably, in recent years, a new class of porous crystalline materials known as 
metal-organic frameworks (MOFs) has been shown to provide high capacities and wide customization options in the capture of iodine and noble gases.

In the present review article, we focus on several porous sorbents (traditional and newly developed), including an overview of promising MOFs for the capture of volatile radionuclides especially for iodine, krypton and xenon. Concerns and limitations of existing sorbents with operating conditions and their capacities for the capture of target species are also discussed.

\section{Background}

Fig. 1 shows the waste releases during various stages of the nuclear fuel cycle. Burger and Burns [15] reported that a small amount of elemental iodine is released from nuclear reactor due to fuel damage, but this is expected to have insignificant effect on overall iodine emissions from the fuel cycle during normal operations. Comparatively, large amounts of offgas can be released during reactor accidents involving broad fuel ruptures. There are three main stages where off-gas released during reprocessing operations: (a) voloxidation off-gas (b) dissolver off-gas (DOG), and (c) vessel off-gas (VOG) [15, 16].

The voloxidation process involves heating of the oxide fuel with oxygen at high temperature. The lattice structure of the uranium oxide fuel breaks down during the conversion of $\mathrm{UO}_{2}$ to $\mathrm{U}_{3} \mathrm{O}_{8}$, and results in the release of gaseous fission products. A large amount of tritium is released and can be recovered from voloxidation. Unfortunately, volatile iodine, technetium, and carbon $\left({ }^{14} \mathrm{C}\right)$ gases are also released concomitantly $[16,17]$.

The DOG emissions occur during the processing of UNF for the recovery of uranium, plutonium, and minor actinides from UNF. In a typical process, UNF is immersed into high temperature nitric acid solution until the fuel is dissolved. This nuclear waste practically contains almost all periodic elements derived from the fission of uranium. The dissolved UNF releases considerable quantities of volatile and gaseous radionuclides including: ${ }^{3} \mathrm{H}$, 
${ }^{14} \mathrm{C}$, iodine $\left({ }^{129} \mathrm{I} \&{ }^{131} \mathrm{I}\right)$, and noble gases $\left({ }^{85} \mathrm{Kr}-40 \mathrm{ppm}\right.$ and $\left.{ }^{133} \mathrm{Xe}-400 \mathrm{ppm}\right)$. Nitrogen ( $80 \%$ ), oxygen $(0-20 \%)$, and various impurities such as $\mathrm{NOx}$ gas $\left(\mathrm{NO}, \mathrm{N}_{2} \mathrm{O}, \mathrm{NO}_{2}\right)$, carbon dioxide, nitric acid, water vapor $(1.2-5$ vol\% $)[18,19]$, traces of hydrogen, and hydrocarbons are also present in the stream [16]. The iodine in the fuel element is assumed to be iodide $\left(\mathrm{I}^{-}\right)$, when contacted with nitric acid it forms elemental $\mathrm{I}_{2}$ due to rapid oxidation. Most of the iodine then evaporates as a result, while some remains in the nitric acid solution. Nonvolatile iodate $\left(\mathrm{IO}_{3}^{-}\right)$also forms as a result of oxidation of iodine in the liquid phase.

VOG emissions consist of off-gases from other equipment used in the reprocessing operations, such as, extraction cells, condensers, leaching tanks, and feed tanks. The off-gases contain iodine (either elemental iodine or organic compounds such as methyl iodide) as well as krypton at much lower concentrations that those in the DOG [16]. These contaminants may be separated through various techniques before emission into the environment. In this article methods for the removal of radioactive iodine, krypton, and xenon from reprocessing facility off-gases are detailed, focusing specifically on the DOG emissions.

\section{Capture of radioactive contaminants by wet processes}

Two classes of separation processes are used to remove radioactive iodine from offgas: wet and dry processes. Wet processes typically use a solvent to scrub iodine from the gas phase. These include alkaline scrubbing, electrolytic scrubbing, and Mercurex and Iodox processes, fluorocarbon absorption, silicon-organic solvent, and molten hydroxide. Solvent selection depends on the method used [16]. A few promising techniques are briefly explained below.

Alkaline (or caustic) scrubbing is well-known processes used at both the La Hague Reprocessing Facility in France, and the THORP facilities in the UK. McKay et al. [17] report on the alkaline scrubbing process using $\mathrm{NaOH}(1-2 \mathrm{M})$ as a solvent. The solvent reacted with both organic and nonorganic iodine species to form new sodium-iodide 
compounds (NaI). If the gas stream contains significant amount, precipitation of sodium carbonate may occur if the solubility is exceeded. This problem can be avoided by using $\mathrm{KOH}$ as an alternative solvent because solubility of potassium carbonate in water $(1.110 \mathrm{~kg}$ $\left.\mathrm{L}^{-1}\right)$ is considerably higher than that of the sodium compound $\left(0.215 \mathrm{~kg} \mathrm{~L}^{-1}\right)$ [20]. The Mercurex and Iodox processes remove organic and elemental iodine from gas stream by adsorbing the iodine in nitric acid. Mercurex employs a mercuric nitrate-nitric acid solution $\left\{0.4 \mathrm{M} \mathrm{Hg}\left(\mathrm{NO}_{3}\right)\right.$ and $\left.\sim 14 \mathrm{M} \mathrm{HNO}_{3}\right\}$ in a packed column to form mercury iodate and other iodide complexes. The mercury must then be separated from the iodine and the resulting precipitant is conditionioned for storage [21]. Holladay [22] and Jubin [23] reported on the Iodox process for the removal of iodine from off-gas using $\mathrm{HNO}_{3}$ (hyperazeotropic) solution. The primary reactions are as follows:

$$
\begin{aligned}
& 2 \mathrm{CH}_{3} \mathrm{I}+4 \mathrm{HNO}_{3} \leftrightarrow 2 \mathrm{CH}_{3} \mathrm{NO}_{3}+\mathrm{I}_{2}+\mathrm{N}_{2} \mathrm{O}_{4}+2 \mathrm{H}_{2} \mathrm{O} \\
& \mathrm{I}_{2}+\mathrm{HNO}_{3}+\mathrm{H}_{2} \mathrm{O} \leftrightarrow \mathrm{HNO}_{2}+2 \mathrm{I}^{+}+2 \mathrm{OH}^{-} \\
& \mathrm{I}^{+}+3 \mathrm{HNO}_{3}+\mathrm{NO}_{3}^{-} \leftrightarrow \mathrm{H}^{+}+\mathrm{IO}_{3}^{-}+2 \mathrm{~N}_{2} \mathrm{O}_{4}+\mathrm{H}_{2} \mathrm{O}
\end{aligned}
$$

Fluorocarbon absorption is another technique for the removal the radioactive iodine from the reprocessing off-gas stream. Experimental investigations were conducted on a packed column using fluorocarbon solvent (dichlorodifluoromethane used at Oak Ridge National Laboratory) at temperatures ranging from 242 to $285 \mathrm{~K}$ and 300 psig pressure. The solvent does not appear to suffer any detrimental effects of contacting $\mathrm{NO}_{2}$, in fact, tests have shown that $97-99 \%$ of the $\mathrm{NO}_{2}$ is retained in the solvent $[24,25]$.

Iodox and Mercurex processes have achieved high DFs (Decontamination factors: ratio of initial to final radioactivity that results from separation process) especially at high iodine concentrations of upto $10^{6}$ and $10^{4}$ respectively; this is compared to DFs of $50-150$ typical of the caustic scrubbing process [26]. However, the corrosive nitric acid in these processes makes equipment subject to corrosion cracking, or alternately the equipment must 
be constructed of nitric acid compatible materials (such as tantalum) which leads to high costs. Additionally, the removed iodine is in a solid form (water-soluble), which need further processed to complete immobilization. The most common conversion immobilizes the solid iodine in a barium iodate cement matrix through a reaction with $\mathrm{Ba}(\mathrm{OH})_{2}$. Fluorocarbon absorption has similar issues with equipment corrosion. Caustic scrubbing may avoid this equipment pitfall with acceptable DFs, but the alkaline solutions tend to absorb $\mathrm{CO}_{2}$ over time, decreasing the effectiveness of the method, and also may not effectively remove organic iodides [27]. Thus, high amounts of solvent must be used to combat this and retain an acceptable DF [12].

Krypton and xenon (noble gases) are other harmful contaminants released in the reprocessing operation. Several competing and promising techniques are available for removal of these gases: cryogenic distillation, absorption, membrane separation and adsorption. Cryogenic distillation is a well-known process in many countries because it is commonly used in the air products industry [28, 29]. Earlier, this technique was used in United States for capture of krypton [30]. However, it requires a pretreatment of the process gas. Nitrogen dioxide among other impurities must be removed with the use of a caustic scrubber. The remaining off-gas contains $\mathrm{NO}_{\mathrm{x}}, \mathrm{Kr}, \mathrm{Ar}, \mathrm{Xe}, \mathrm{H}_{2}$ and $\mathrm{O}_{2} . \mathrm{NO}_{\mathrm{x}}$ is then reduced to nitrogen and water by passing the gas through a rhodium catalyst bed at $813-923 \mathrm{~K}$. After drying, the gas stream is contacted with liquid nitrogen in a countercurrent absorption column transferring $\mathrm{Kr}, \mathrm{Xe}, \mathrm{Ar}$, and remaining $\mathrm{O}_{2}$ into the liquid nitrogen phase. The high-pressure operation results in increasing safety concerns due to high concentration of radioactive materials. The distillation process is a heavily energy intensive process with high operation costs. In addition, the distillation step facilitates the accumulation of highly explosive ozone. $[31,32]$. 
Fluorocarbon absorption is another attractive technique for the absorption of krypton and xenon. Precooled off-gas stream is bubbled through a fluorocarbon $-12\left(\mathrm{CCl}_{2} \mathrm{~F}_{2}\right)$ solvent and $\mathrm{Kr}$ and $\mathrm{Xe}$ are transferred into the liquid phase. Ozone accumulation is avoided in this process, however, the solvent carryover into the product streams, and radiolysis results in possible corrosion of the column construction material. Furthermore, this separation is less selective for $\mathrm{Kr} / \mathrm{Xe}$ leading to higher gas waste volume [32]. Stern and Wang reported upon the separation of gases by membrane process based on large pressure difference between in

noble gases, air, and other radioactive concentrated contaminants [33]. The separation of gases with membrane technique has been possible only at the laboratory scale because preparation of uniform organic membranes is very difficult. The organic membrane can potentially react with the radioactive materials losing its separation characteristics, which is another impediment to the application of membrane separation. Adsorption on porous solid sorbent is an effective dry technique for the removal or capture of harmful radioactive gases, and is discussed in detail in the following section.

\section{Capture of radioactive contaminants by dry processes (adsorption)}

Adsorption is one of the effective unit operations to capture the volatile radioactive contaminants from gas streams. Adsorption is a well-established technique that is more powerful and advantageous than wet processes due to its simplicity, reliability, noncorrosive nature, simple design, and low maintenance and operating costs. The waste product obtained at the end is in a dry form that is easy to handle $[15,16,23,34]$. The preparation of effective sorbent and its cost are the major challenges for this technique. Traditional solid sorbents used for the capture of iodine and $\mathrm{Kr} / \mathrm{Xe}$ are discussed separately followed by a discussion of the novel MOF sorbents.

\subsection{Sorbents for capture of radioactive volatile iodine}


Table 1 shows the iodine adsorption capacity or removal efficiency of sorbents at different conditions investigated by various researchers over the last 21 years. Activated carbon (AC) is used worldwide as an effective sorbent due to its high surface area and pore size. The capacity of AC can be enhanced by several techniques such as the selection of raw materials (coal, bamboo, coconut and walnut shells) used to synthesize the AC, method of preparation and activation, and impregnation of other compounds and entities (triethylenediamine TEDA and silver), changing functional group and phenolic group [3539]. Park et al. [35, 36] reported on the adsorption of methyl iodide on AC and TEDAimpregnated $\mathrm{AC}$ in a continuous gas phase system. Notably, AC had excellent sorption capacity (320 mg g ${ }^{-1}$ ) at $303 \mathrm{~K}$ compared to other sorbents. Nevertheless, the sorbent capacity decreased with an increase in temperature [37]. Zeocarbon (AC 40\% + zeolite 60\%) also showed similar results but it was observed to have higher desorption rates than adsorption at high operating temperatures. The bamboo (raw material) charcoal had $70 \%$ efficiency in single pass which was higher than the any other sorbent such as anthracite and commercial coconut AC, possibly due to the numerous micropores that would be effective in adsorption of small non-polar gaseous ${ }^{131}$ I molecules [38].

TEDA-impregnated AC (derived from walnut shells) and carbon activated by carbon dioxide (1123 $\mathrm{K}$ for $120 \mathrm{~min}, \mathrm{AC} / 120)$ were found to be active for the sorption of radioactive methyl iodide. However, the capacity of AC increased mainly after impregnation of TEDA because it was accompanied by the chemical interactions between TEDA and $\mathrm{CH}_{3} \mathrm{I}$ to form stable ammonium salt, which remains fixed to the porous structure of sorbent. The 5\% TEDA loaded on AC/120 sorbent had $98.1 \%$ removal efficiency of methyl iodine from humid air stream at $303 \mathrm{~K}$ and 1 atmosphere [40]. Previous literature stated that the TEDA and KI/KOH increased the protection/breakthrough time of sorbent mainly due to isotopic exchange with radioactive iodine [41]. However, this effect is not observed for elemental iodine because the 
capacity of AC is totally dependent upon the surface area and pore size of the sorbent $[42$, 43]. Jubin [26] reported that AC (with or without impregnation) is not effectively used in offgas generated from Used Nuclear Reprocessing plant, because off-gas stream contains nitrogen oxide which decreases the retention of iodine and leads to explosive reactions in the sorbent beds. Nitrogen oxide may also have low ignition point and adversely affect the performance of AC.

As stated above, $\mathrm{AC}$ has been found as a potential sorbent for iodine entrapment, but it has several issues such as decreased capacity and chances of explosion, therefore, other porous sorbents have been widely investigated. Silver impregnated alumina, silica and zeolite based sorbents are active porous materials for the capture of iodine species having significant iodine sorption capacity at high temperatures (423 K). Wilhelm and Furrer [44] reported on $\mathrm{Ag}$ adsorbents containing silver in the form of $\mathrm{AgNO}_{3}$ for the removal of $\mathrm{I}_{2}$ and $\mathrm{CH}_{3} \mathrm{I}$ from the reprocessing plant off-gas. $\mathrm{AgNO}_{3}$ reacted with elemental iodine to form the stable silver iodide/iodate. Fukasawa et al. [12, 45] developed a silver nitrate impregnated alumina sorbent (24\% AgA). The capacity of sorbent was investigated for capture of iodine from a reprocessing plant using continuous column at a velocity of $20 \mathrm{~cm} \mathrm{~s}^{-1}$ at $423 \mathrm{~K}$. They concluded that parameters (iodine concentration, gas flow rate) other than temperature had no effect on decontamination factor (DF's). High DF's were observed at high temperatures. The capacity of sorbent was $\sim 0.22 \mathrm{~g} / \mathrm{g}-\mathrm{AgA}$, which utilized about $78 \%$ of silver in the sorbent. Silver nitrate impregnated adsorbents provide high DF for elemental and organic iodides at high temperatures and provide a high-percentage utilization of the silver. The adsorbent exhibits high resistance to NOx, and moderate concentrations of $\mathrm{NO}_{2}$ (1 to $\left.10 \%\right)$ actually appear to enhance the performance by preventing the silver from being reduced to the elemental state. However, a large amount of organic contaminants can adversely affect the adsorbent performance in the absence of sufficient $\mathrm{NO}_{2}$ and removal efficiency is 
significantly reduced by high humidity, i.e. dew-point temperature excursions. Sakurai et al. reported the silver-impregnated silica-gel $(\mathrm{AgS})$ sorbent was used to trap ${ }^{129} \mathrm{I}$ in cartridge filters [46]. Mineo et al. [47, 48] developed a mathematical model for the removal of ${ }^{129} \mathrm{I}$ from the dissolver off-gas treatment on silver nitrate - silica gel packed bed. Gaseous iodine was removed using silver-impregnated alumina $\left(\mathrm{Ag} / \mathrm{Al}_{2} \mathrm{O}_{3}\right)$ at different temperatures (373 $923 \mathrm{~K})$; the sorbent was active at high temperatures during nuclear accident [49].

Silver-exchanged zeolite is widely used as a sorbent for capture of iodine because it is mechanically strong, has high efficiency and high loading capacity. Zeolite is an aluminosilicate with a framework structure containing cations and enclosing cavities, called as supercages [50]. The pore diameter is in the range of $3-10 \AA$. The number of exchanged cations influences the capacity and efficiency of the sorbent. This sorbent shows a great iodine sorption capacity in moist atmosphere (flow conditions) compared to other reported metal-exchanged sorbents (cadmium, copper, mercury, and lead). Soelberg and Watson [51] investigated deep-bed iodine sorption on $30 \mathrm{wt} \%$ silver-functionalized aerogel (BET surface area $-200 \mathrm{~m}^{2} \mathrm{~g}^{-1}$ ) and silver zeolite. Breakthrough experiments were performed for removing methyl iodine from moist and NOx-containing gases. Iodine adsorption tests were performed on aerogel and silver zeolite with the inlet iodine concentration ranging from 2 - 34 ppmv and 1.6 - 49 ppmv, respectively. The highest inlet iodine concentration resulted in the highest iodine loading due to the chemical reaction between the silver and iodine to form non-volatile AgI. The silver-functionalized aerogel and silver zeolite adsorbed $20-46$ and $3.3-17 \mathrm{wt} \%$ of iodine/100 g sorbent, respectively.

Patton et al. [52] investigated the performance of the silver exchanged mordenite (M) sorbent for gas stream in presence water vapor, nitric acid vapor, gaseous nitrogen oxide (NO) and other contaminants. A $9.5 \mathrm{wt} \% \mathrm{Ag}^{0}-$ mordenite $\left(\mathrm{Ag}^{0} \mathrm{M}\right)$ was developed [53]. Iodine sorption experiments were performed at $423 \mathrm{~K}$ with the inlet iodine concentration of 
$50 \mathrm{ppm}$. The samples were removed at one week and one month of operation. The iodine capture capacity of sorbent decreased by $78 \%$ in NO-aged $\mathrm{Ag}^{0} \mathrm{M}$, observed in the first week of exposure to $1 \% \mathrm{NO}$. The exposure to $1 \% \mathrm{NO}$ and air appears to cause the silver material to lose the majority of its iodine capture capacity. The capacity loss appears to be greater than oxidation of the silver in the sample. Several other research groups have also focused on the silver modernite. Nenoff and co-workers [19] proposed a theory of adsorption of iodine on silver-modernite. Fig. 2 displays the proposed mechanism of chemical reactions occurring during capture of iodine from input stream $\left(\mathrm{CH}_{3} \mathrm{I}, \mathrm{H}_{2} \mathrm{O}, \mathrm{NO}, \mathrm{NO}_{2}\right.$ and air). Methyl iodine $\left(\mathrm{CH}_{3} \mathrm{I}\right)$ decomposed to form an iodine species. Surface methoxy species (SMS) were observed at low operating temperature of the adsorption process $(423 \mathrm{~K})$. Inside the zeolite pore, iodine reacted with Ag nanoparticles to form AgI. Furthermore, surface methoxy species reacted with water to form methanol or with NOx to form methyl nitrite, which can further react with other SMS to form dimethyl ether. Chapman et al. [54] also examined the silver exchanged mordenite $\left(\mathrm{Ag}^{+}-\mathrm{M}\right.$ and $\left.\mathrm{Ag}^{0}-\mathrm{M}\right)$ for iodine capture at $368 \mathrm{~K}$ for $12 \mathrm{~h}$. Kuznicki and co-workers [55] have recently developed silver deposited titanosilicate ETS-10 and sodium nanotitanate ETS-2 porous sorbents to capture the iodine under humid conditions. Their experimental results indicate that silver is more reactive towards iodine sorption. Ag-ETS-2 adsorbed $24.3 \mathrm{wt} \%$ iodine in wet conditions, this capacity was higher than Ag-ETS-10. Ag-ETS-2 reaction with iodine to form AgI is shown as below:

$$
6 \mathrm{AgTiO}_{3}+3 \mathrm{I}_{2} \longrightarrow 4 \mathrm{AgI}+2 \mathrm{AgIO}_{3}+6 \mathrm{TiO}_{2}
$$

The immobilization of $\mathrm{I}_{2}$-loaded sorbent is essential step for the long-term storage of sorbent due to volatile nature of iodine. The Hanford Waste Treatment and Immobilization Plant (WTP) was built at the Hanford site (Washington State, U.S.A.) to store high-level radioactive wastes to comply with the United State Environmental Protection Agency (EPA) air emission regulations [56]. WTP planned to use silver mordenite to control releases of 
volatile radioactive iodine, followed by the solidification of the sorbent using 65 mass $\%$ ASTM Portland Type III cement. The $\mathrm{CaI}_{2}$ would be effective modifier; the cement was used to solidify and stabilize trapped iodine on silver sorbents via reprocessing gas stream. Garino et al. [57] reported on the encapsulation of AgI or AgI-zeolite such as AgI-mordenite (AgIM) sorbent using low temperature glass composite materials (GCM). GCM was selected because of two reasons: (1) sintering temperature of glass is below the volatilization temperature of captured iodine by silver (AgI), and (2) low temperature results in a lower energy input during sintering. The Ag-M trapped the iodine vapor at $363 \mathrm{~K}$ forming AgI-M. Then, it was mixed with $20 \%$ bismuth-silicon-zinc (Bi-Si-Zn) oxide glass powder and additional $5 \mathrm{wt} \%$ silver flakes were added; the mixture was pressed in a steel die (pressure $70 \mathrm{MPa})$ to form pellets. Silver flakes served to capture of any iodine released from heating. The chemical durability of GCM glass (Bi-Si-glass (80 wt $\%) / \mathrm{AgI}-\mathrm{M}(20 \mathrm{wt} \%) / \mathrm{Ag}+5 \mathrm{wt} \%)$ was higher than any Pyrex glass, which was confirmed by product consistency test (PCT). In addition, the core/shell structure was used to further minimize the potential for introduction of iodine. AgI or AgI-M was contained into the core and dense glass completely surrounded as a shell to prevent the contact between iodine and environment. The coefficient of thermal expansion of the shell was lowered by addition of amorphous silica to prevent the crack formation in core/shell structure due to thermal expansion mismatch between core and shell.

Alternative porous sorbents have been investigated for off-gas treatment at reprocessing facilities on the basis of waste loading, affinity, and economics. Aerogel prepared sorbents are introduced due to high thermal stability, porosity, and gas sorption capacity [58]. Lian and coworkers [59] developed two sorbents, namely, graphene powder and graphene aerogel via hummers and hydrothermal techniques, respectively. Iodine uptake experiments were performed in a desiccator. Their results showed that the pristine graphene powder adsorbed maximum $80 \%$ iodine at $298 \mathrm{~K}$ due to higher surface area, $1272 \mathrm{~m}^{2} \mathrm{~g}^{-1}$ 
graphene sorbent. Graphene aerogel (surface area $508 \mathrm{~m}^{2} \mathrm{~g}^{-1}$ ) had improved iodine sorption capacity (> $100 \%$ mass gain) over pristine graphene powder. The higher iodine sorption capacity observed in graphene aerogel at relatively lower specific surface area was attributed to the pore shape and size of the highly porous graphene aerogel. The activation energy of iodine sorption was calculated to be $70.63 \mathrm{~kJ} \mathrm{~mol}^{-1}$ at $298-343 \mathrm{~K}$. Riley et al. [60-62] and Subrahmanyam et al. [63] reported upon chalcogen-based aerogels, polyacrylonitrilechalcogel hybrid and chalcogenide sorbents for the remediation of radioactive iodine, respectively. They concluded that the chalcogels (PtGeS, MoCoNiS and SnS) and polyacrylonitrile-chalcogels hybrid sorbent indicated very high capture efficiencies of $>99 \%$ and $>99.3 \%$ for iodine gas sorption. Other than aerogel, bismuth based [64] and bismuthembedded SBA-15 mesoporous silica [65] sorbents were also tested for treatment of off-gas stream. Bismuth had a higher iodine removal capacity $\left(\sim 0.47 \mathrm{~g} \mathrm{~g}^{-1}\right)$ than the silver exchanged zeolite due to high thermodynamic stability of reaction products, $\mathrm{BiOI}$ and $\mathrm{BiI}_{3}$ at $473 \mathrm{~K}, \Delta G$ of -219.5 and $-139.7 \mathrm{~kJ} \mathrm{~mol}^{-1}$, respectively. The bismuth-embedded SBA-15 had maximum adsorption capacity of $540 \mathrm{mg} \mathrm{g}^{-1}$ due to the strong reaction affinity of bismuth sulfide with iodine and high surface area of SBA-15. A comparative study of silica supported $\mathrm{Cu}$ nanoparticles $(\mathrm{Si}-\mathrm{N}-\mathrm{Cu})$ and micrometric copper powder $(\mathrm{Mi}-\mathrm{Cu})$ for sorption of iodine vapor has been conducted. The nanosized $(29.4 \mathrm{~nm})$ copper adsorbed $95 \%$ of $\mathrm{I}_{2}$ at partial pressure $10^{-5}$ bar and $503 \mathrm{~K}$ in $1 \mathrm{~h}$, this capacity was higher than $1 \mu \mathrm{m}(\mathrm{Mi}-\mathrm{Cu})$ sorbents $\left(51 \% \mathrm{I}_{2}\right.$ adsorb at $6 \mathrm{~h}$ ). The results indicate that the copper nanoparticles had a higher yield and faster kinetics for iodine adsorption $\left(\mathrm{Cu}-\mathrm{I}_{2}\right)$ because diffusion does not impact kinetics. The kinetics in the $\mathrm{Mi}-\mathrm{Cu}$ is governed by diffusion in the shrinking core model, which reduces the rate of reaction between $\mathrm{Cu}$ nanoparticles and $\mathrm{I}_{2}$ with time [66].

In recent years, Utgikar and co-workers developed active and economical sorbent, namely, Engelhard titanosilicate - 10 supported nanostructured hollow carbon (10 wt\% 
C@ETS-10) for capture of iodine gas molecules [67]. The BET surface area and pore size diameter of the sorbent were observed to be $149 \mathrm{~m}^{2} \mathrm{~g}^{-1}$ and $39 \mathrm{~nm}$, respectively. Column breakthrough experimental results showed that the prepared sorbent was effective at low temperature $(293 \mathrm{~K})$ without any chemical bonding between the elemental iodine $\left(40 \mathrm{mg} \mathrm{g}^{-1}\right)$. The experimental sorption data were modeled using a Langmuir adsorption isotherm type relationship between sorption capacity and empty bed contact time, EBCT (Fig. 3). Nandanwar et al. developed $\mathrm{MgO}$ nanostructured porous sorbent for capture of iodine $\left(\mathrm{I}_{2}\right)$ at room temperature; result strongly imply the $196 \mathrm{mg} \mathrm{g}^{-1}$ of iodine was adsorbed on sorbent based on surface area and pour size of sorbent [68].

The foregoing discussion clearly indicates that the metal (silver, bismuth, copper) based sorbents are effective for capture of the radioactive iodine from off-gas stream at high temperature. These results show promise for immobilization of iodine with mordenite (AgI) in GCM glass. However, silver metal sorbents are much more expensive and potentially hazardous to the environment. The capture and removal of contaminants using sorbent containing silver involves chemical reaction between the iodine molecules $\left(\mathrm{I}_{2}\right.$ and $\left.\mathrm{CH}_{3} \mathrm{I}\right)$ and the metal on the surface of the sorbent. The capacity of this type of sorbent is dependent on the active sites of metal on the surface of the support. Metal atoms embedded within the sorbent or inserted deep into the pore of supports (alumina, zeolite, mordenite, SBA-15) may not be accessible to iodine, resulting in a decreased sorption capacity. In addition, iodine trapped into the solid waste still needs further processing to complete disposal/long-term storage. The developed structure of carbon aerogel and C@ETS-10 may work, as the effective sorbent but still it needs further research.

\subsection{Sorbents for capture of radioactive krypton and xenon}

$\mathrm{Kr}$ and $\mathrm{Xe}$ have similar chemical behavior; most adsorbents that capture $\mathrm{Kr}$ will inadvertently adsorb $\mathrm{Xe}$ as well. Making the separation of $\mathrm{Xe}$ and $\mathrm{Kr}$ a nontrivial task. With 
Xe being present at about 10 times that of $\mathrm{Kr}$ and more polarizable (thus more reactive in many cases), $\mathrm{Kr}$ may be susceptible to being outcompeted for the available adsorption sites or being displaced on adsorption sites by Xe. Thus the following literature survey of solid sorbents includes the results of sorbents for both $\mathrm{Kr}$ and $\mathrm{Xe}$, and some discussion on their competitive adsorption. Defining selectivity provides a measure of how effective a sorbent is for the removal of one component. The selectivity of a sorbent for $\mathrm{Xe}$ over $\mathrm{Kr}$ is shown by following Eq:

$$
S e_{X e / K r}=\frac{x_{X e} / y_{X e}}{x_{K r} / y_{K r}}
$$

Where $x_{i}$ is the mole fraction in the adsorbed phase, and $y_{i}$ is the mole fraction in the effluent gas for species ' $i$ '.

AC has traditionally been the primary choice as a $\mathrm{Kr}$ sorbent as it was for $\mathrm{I}_{2}$; it is a low cost material with a high surface area. AC also makes an excellent sorbent because the activation process creates slot-like pores creating many active sites available for adsorption, and the strength of the bonds to these sites is increased because of the natural surface defects in AC, which are comprised of non-compensated bonds [69]. This makes the sorbent capacity of AC benchmarks for comparing the performance of other sorbents. A key reason other sorbents are sought to replace $\mathrm{AC}$ as a sorbent for off-gas is that the $\mathrm{Kr}$ must be further separated from the $\mathrm{AC}$ for radioactive storage. This is done using temperature swing adsorption (TSA), and in the high temperature conditions of TSA volatile reactions between the $\mathrm{AC}$ and $\mathrm{NO}_{\mathrm{x}}$ compounds can occur, causing explosive reactions [70 - 72]. The capacities of various sorbents for $\mathrm{Kr}$ at a different range of temperatures are listed in Table 2.

Munakata et al. [73] reported that the carbon based adsorbents had large adsorption capacities for $\mathrm{Kr}$, especially Ambersorb 572 having the largest adsorption capacity. Adsorption isotherms for these sorbents obeyed the Henry's law when the partial pressure of 
$\mathrm{Kr}$ was less than $100 \mathrm{~Pa}$ at liquid argon temperature in nitrogen carrier gas. This is possibly due to carbon based sorbent having a larger affinity for krypton as compared to nitrogen.

Single-walled carbon nanotubes (SCNTs) have been studied as sorbents due to their physical and chemical properties such as high surface area, uniform pore size and thermal stability. Muris et al. [74] studied the capture of methane and krypton on single-walled carbon nanotubes. $\mathrm{Kr}$ adsorption isotherm at $77.3 \mathrm{~K}$ showed two distinct steps with increasing pressure, which were attributed to $\mathrm{Kr}$ adsorbing first to the interstitial channels, then the exterior walls of the nanotubes. The single-walled carbon nanotubes exhibited a capacity of $2.6 \times 10^{-3} \mathrm{~mol} \mathrm{~g}^{-1}$ at $\mathrm{Kr}$ partial pressure of $10 \mathrm{~Pa}$, a two-fold increase over the capacity of graphite at the same conditions. Xe and Kr sorption on SCNTs has also been explored using Molecular Dynamic (MD) simulation by Jalili et al. [75]. It was found that the opening of the CNTs had a large impact on the adsorption characteristics, because the gases adsorb on the inner walls of the opened CNTs. Coverage of $\mathrm{Kr}$ and $\mathrm{Xe}$ was found at temperatures ranging from 100 to $130 \mathrm{~K}$. Isosteric heat of adsorption data were used to find binding energies for $\mathrm{Xe}$ and $\mathrm{Kr}$, which were 0.70 and $0.47 \mathrm{~kJ} \mathrm{~mol}^{-1}$, respectively. While capacities were not reported, the exohedral heat of adsorption was at $3 \mathrm{~kJ} \mathrm{~mol}^{-1}$ for xenon and $1.4 \mathrm{~kJ} \mathrm{~mol}^{-1}$ for krypton. Additionally, they report $\mathrm{Xe}$ and $\mathrm{Kr}$ fractional coverage extents to be 0.23 and 0.25 (noble gas per carbon atom), respectively. This exciting development shows that SCNTs have highly desirable characteristics for the adsorption of these noble gases. Still, xenon has a larger heat of adsorption more than twice that of krypton, boding well for the selective adsorption of xenon on the SCNTs. As such SCNTs have potential to remove Xe in preliminary adsorption steps with a relatively inexpensive material, especially if low-cost carbon nanotube fabrication processes are developed.

As noted in the previous discussion, porosity, surface area, and functionalization are important properties when considering adsorbents for noble gases. Aerogels are also 
considered due to their physical properties as mentioned in the iodine sorption section. The sol-gel process used to create aerogels allows for the alteration of chemical makeup, modification of the organosilane and deposition of chemical layers. This allows the micropores in aerogels to be highly customizable and effective for the removal of radionuclides [76]. Zeolites attract a great interest in the field of noble gas sorption due to their physical properties (high specific capacity, structural stability and small pore size). Hydrogen-mordenite (HM) is a zeolite of interest for the removal of $\mathrm{Kr}$ because of its apparent high capacity for Kr. Ianovski et al. [70] investigated HM for $\mathrm{Kr}$ sorption. HM was created by ion exchanging mordenite in $\mathrm{HCl}$. It was concluded that the adsorption capacity of $\mathrm{HM}$ for $\mathrm{Kr}$ was about four times greater than Molecular Sieve 5A and two times higher than that of the natural mordenite, and comparable to $\mathrm{AC}$ at $195 \mathrm{~K}$ in helium carrier gas. The adsorption $(\mathrm{Kr})$ capacity of $\mathrm{HM}$ was enhanced by the change into large-pore type mordenite and the removal of extraneous materials in the mordernite channels and an increase in the surface area formed of the Si-O-Si bond by dealuminization.

Garn et al. [77] have presented a more detailed study on HM for sorption of Kr. An important step in the process was the pelletization of HM. Although, the powder form of mordenite has surface area in excess of $500 \mathrm{~m}^{2} \mathrm{~g}^{-1}$, the use of powder in the operation of adsorption column leads to a large pressure drop. Pelletization of the powder reduces pressure drop, but at the expense of the surface area. Typical commercial silver mordenite has a surface area around $30-50 \mathrm{~m}^{2} \mathrm{~g}^{-1}$. A method was developed to form pellets with a BET surface area of $336 \mathrm{~m}^{2} \mathrm{~g}^{-1}$ using a polymer binder. It was found that HM had a sorbent capacity of $100 \mathrm{mmol} \mathrm{kg}$ at a concentration of $150 \mathrm{ppm}$ balanced with helium. The sorbent capacity is considered to be quite high. HM was also shown to have high thermal stability, proving suitable for thermal regeneration cycles. However, the addition of Xe to the inlet gas in the concentration of $1000 \mathrm{ppm}$ reduces the $\mathrm{HM} \mathrm{Kr}$ capacity to $7.41 \mathrm{mmol} \mathrm{kg}^{-1}$. This 
problem is avoided by the use a second zeolite-silver mordenite (AgM) to trap Xe before the process gas was passed through the HM column. In recent years, Daniel et al. studied five commercially available zeolites loaded with silver and the Xe adsorption isotherms were obtained over a wide range of pressures. Increasing Ag loading showed a direct correlation to an increase of strong adsorption sites, located on the exterior of the porous zeolites. This increase of strong bonding sites also improves adsorption at lower pressures. Experimentally observed capacities were quite good: at $303 \mathrm{~K}$ and 100 ppm Xe, Ag-PZ2-25 had a capacity of $5 \times 10^{-4} \mathrm{~mol} \mathrm{~g}^{-1}$, compared to the traditionally used active charcoal capacity of $4.3 \times 10^{-6} \mathrm{~mol} \mathrm{~g}^{-1}$ [78].

Silver-mordernite sorbent is also remarkable for capture of radioactive Kr. AgM (BET surface area $\left.-109 \mathrm{~m}^{2} \mathrm{~g}^{-1}\right)$ had higher krypton adsorption capacity $\left(\sim 10^{-4} \mathrm{~mol} \mathrm{~g}^{-1}\right)$ than carbon based sorbent in helium carrier gas at a $\mathrm{Kr}$ partial pressure less than $1000 \mathrm{~Pa}$ and $273 \mathrm{~K}$. Changes occurring in the electrostatic potential on the surface of natural mordenite were considered to enhance the affinity of surface for the noble gases $[70,79]$. The opposite trend was reported under nitrogen atmosphere at liquid cryogenic conditions [34]. The loading of silver nanoparticles onto zeolites or silicotitanate has been reported to result in an increased affinity over the non-modified parent materials for noble gases. This $\mathrm{Ag}^{+}$metal center interacts with the noble gas in what is described as a weak Lewis acid (metal)/base (noble gas) affinity [76]. Kuznicki et al. reported the strong interaction on Ag-ETS-10 to a specific interaction of xenon with silver nanoparticles observed at the external surface of zeolite. In addition, the highest reported heat of adsorption value was between $40-90 \mathrm{~kJ} \mathrm{~mol}^{-1}$ [80].

Utgikar and co-workers [81] investigated ETS-10 supported hollow carbon nanostructure sorbent for krypton capture. Adsorption experiments were conducted at ambient temperature and pressure to obtain dynamic sorption capacity through continuous column experimentation. Fig. 4 shows the breakthrough sorbent capacities of prepared 
sorbents compared to coconut AC at same conditions. The operational capacity of $10 \mathrm{wt} \%$ C@ETS-10 was found to $0.45 \mathrm{mmol} \mathrm{kg}^{-1}$, which was $\sim 15 \%$ higher than the AC at $263 \mathrm{~K}$. Notably, C@ETS-10 porous sorbent can be used for adsorption of both contaminants (iodine and krypton). This sorbent may effectively work in treatment of both contaminants from offgas generated from Used Nuclear Reprocessing plant because it contained only $10 \mathrm{wt} \%$ carbon nanoparticles onto ETS-10 to reduce or eliminate the explosion hazard with NOx.

Atomistic simulations have been gaining traction recently, and provide an excellent option for the screening of materials to be experimentally tested. For example, Jameson et al. studied the competitive adsorption of $\mathrm{Kr}$ and $\mathrm{Xe}$ on the zeolite NaA using Grand Canonical Monte Carlo (GCMC) simulation [82]. The selectivity of $\mathrm{Xe} / \mathrm{Kr}$ was calculated at $\sim 5$. Calculations such as this give insight into materials that have potential for adsorption, but experimental data eventually must be obtained to verify, validate and discover a better understanding of how these materials perform. Aerogels are promising materials as well, however, they require further processing for immobilization by sintering, and the storage is resource intensive. Hydrogen mordenite also shows great potential in its high capacity for $\mathrm{Kr}$, and silver mordenite for Xe. However, many sorbents in the zeolite family require complicated synthesis steps, making a scale up a challenging proposition. Additionally, the use of silver in these materials remains an issue due to the cost associated with it. In light of these limitations, it is clear that the development of alternative sorbents that are economical and effective must continue.

\subsection{MOF's for capture of radioactive iodine and noble gases}

MOFs are crystalline materials consisting of metal ions or cluster and organic linker, connected by coordination bonds of moderate strength [83]. MOFs have several attractive properties such as porous structure, high surface area, high dispersion of components, intrinsic hybrid nature, topology and gas sorption capacity. Therefore, MOFs have potential 
applications in the fields of gas storage, molecular sensing, separation, ion exchange, electronic device, food packing materials and membrane separation $[84,85]$. In the last few years, a number of researchers have investigated MOFs for capture of iodine from gaseous phase [13] and dissolved iodine from liquid phase [86]. This article focuses upon the removal from the gas phase and the removal of iodine from liquid phase is not discussed herein.

\subsubsection{Radioactive iodine}

Sava et al. [13] developed two MOFs, ZIF-8 (Zeolite imidazolate frameworks) and $\mathrm{Cu}-\mathrm{BTC}$ for capture of volatile iodine gas. ZIF-8 is a tetrahedral coordinated $\mathrm{Zn}$ atoms linked by 2-methylimidazole (MeIM) ligand. Iodine sorption experiments were performed in a hermetically sealed chamber using ZIF-8 (powder) at fuel reprocessing conditions ( $350 \mathrm{~K}$ and ambient pressure with $I_{2}$ vapor pressure of 0.014 atm); equilibrium was reached in $5-12 \mathrm{~h}$. ZIF-8 captured $125 \%\left(1.25 \mathrm{~g}\right.$ of $\left.\mathrm{I}_{2} / \mathrm{g} ; 2.2 \mathrm{I} / \mathrm{Zn}\right)$ of iodine. Actually, iodine sorption on ZIF-8 was mainly due to favorable interaction with MeIM linker. On average, 5.4 iodine molecules were captured into the each cage of framework. Nevertheless, only $25 \% \mathrm{I}_{2}$ was bound on the surface; remaining iodine was effectively contained into the sodalite cages of ZIF-8. In another study, Sava et al. [87] reported Cu-BTC sorbent to capture molecular iodine gas from mixed stream. $\mathrm{Cu}-\mathrm{BTC}$ is well known as HKUST-1 or $\mathrm{Cu}_{3}(\mathrm{btc})_{2}$; it consists of diatomic $\mathrm{Cu}$ centers linked together by 1,3,5-benzene tricarboxylate units to form a three-dimensional cubic structure. Sorption capacity was evaluated in a sealed chamber at $3.5 \%$ relative humidity, ambient pressure and a temperature of $350 \mathrm{~K}$. Highest iodine sorption uptake was $175 \mathrm{wt} \% \mathrm{I}_{2}$ or $3 \mathrm{I} / \mathrm{Cu}$. Fig. 5 represents the interaction of $\mathrm{I}_{2}$-framework and arrangement of $\mathrm{I}_{2}$ molecules inside the cages. The axial paddle wheel water molecules appear to hold the $\mathrm{I}_{2}$ molecules, via tritopic van der Waals interactions, $\mathrm{I} \cdots \mathrm{O}=3.46-3.84 \AA$, in center of the triangular window of the smallest cage (Fig. 5a). Initially, only single molecule of $\mathrm{I}_{2}$ was noticed in $5 \AA$ cage due to very small space (Fig. 5b). $I_{2}$ molecules were observed in the 
middle of the four-ring structure (4.24-4.31 $\AA$ ) (Fig. 5c). At high cage (11 $\AA$ ), $\mathrm{I}_{2}-\mathrm{I}_{2}$ intermolecular interactions were observed (3.94 - $4.27 \AA$ A) (Fig. 5d).

In recent years, the ZIF-8 has been explored by many researches due to substantial iodine sorption capacity [88 - 90]. Chapman et al. [88] reported on the sorption of iodine into ZIF-8 followed by subsequent pressure-induced amorphization to trap the iodine within an amorphous matrix. Iodine was loaded onto ZIF-8 at $348 \mathrm{~K}$; the sample was annealed at $398 \mathrm{~K}$ for 6 to remove iodine from external surface. The $\mathrm{I}_{2}$-loaded ZIF-8 dry powder was amorphized by applying an average pressure of $\sim 1.2 \mathrm{GPa}$ for $1 \mathrm{~min}$ in a pellet press. The long-term durability leach test of amorphized pellet $\left(\mathrm{I}_{2}\right.$-loaded ZIF-8) was tested by heating it in deionized water for $7 \mathrm{~d}$ at $363 \mathrm{~K}$. Their results indicates that amorphization enhanced the durability of iodine at $363 \mathrm{~K}$. On the other hand, the extension of high pressure technique to other ZIFs could be problematic, given the variable responses of ZIFs to applied pressure [89]. Consequently, Bennett et al. studied $\mathrm{I}_{2}$-sorption at $350 \mathrm{~K}$ and retention properties of several ZIFs (ZIF-4, -8, -69 and ZIF-mnIm $\left[\mathrm{Zn}\left(\mathrm{mnIm}_{2}\right)\right] \quad(\mathrm{mnIm} 2=$ 4-methyl-5nitroimidazolate) amorphized by ball milling at room temperature for $20 \mathrm{~min}$. ZIF-8 showed slightly higher iodine sorption capacity than the ZIF-mnIm, possibly be due to the larger porosity of ZIF-8 (3.4 ̊). During the retention, the several changes was noticed in ZIFmnIm, possibly stemming from the role of the methyl group in the 4-ring windows in controlling ingress and egress of adsorbed species [90].

Hughes et al. [91] reported the evidence of strong interaction for iodine sorption on ZIF-8. The analysis test was performed before and after thermal process with $\mathrm{I}_{2}$-loaded ZIF8. Capacities of 0.17 and $0.59 \mathrm{I}_{2} / \mathrm{Zn}$ were observed on the surface and inside the cage, respectively, before thermal treatment. Only $0.59 \mathrm{I}_{2} / \mathrm{Zn}$ was contained in the cage after thermal treatment (398 $\mathrm{K}$ for $1 \mathrm{~h}$ ). The energetics of iodine confinement per $\mathrm{I}_{2}$ in ZIF-8 were $\Delta H_{a d s}=-41.47 \pm 2.03 \mathrm{~kJ} \mathrm{~mol}^{-1} \mathrm{I}_{2}$ within the cage and $\Delta H_{a d s}=-18.06 \pm 0.62 \mathrm{~kJ} \mathrm{~mol}^{-1} \mathrm{I}_{2}$ for 
surface bound iodine. The ZIF-8 cage allows each iodine atom to form two charge-transfer complexes between opposing MeIM linkers, which creates the ideal binding site. The iodine sorption capacity of 12 MOFs was addressed by Grand Canonical Monte Carlo (GCMC) modeling at room temperature. The simulations demonstrated that at low pressure $(p=1 \mathrm{E}-03$ bar), MOFs with small pore volume were more qualified for iodine capture. Higher pore volume of MOFs was desirable at normal pressure. Iodine was adsorbed on the active sites of metal cluster. The capacity of MOFs could be increased by type of materials, structure and density of metal sites. The interaction energy between $I_{2}$ and MOF framework could be enhanced by two way (1) introducing some elements such as $\mathrm{Ag}$ and $\mathrm{Cu}$ with high interaction energy with iodine, and (2) functionalizing the organic linker by a group with good affinity for $\mathrm{I}_{2}[92]$.

Glass composite material is useful for the immobilization of $I_{2}$ loaded MOFs for long term storage of iodine. MOF-containing glass composite material (GCM) was fabricated to store the radioactive ${ }^{129}$ I. Iodine adsorbed onto the two MOFs, ZIF-8 (1200 mg I $\mathrm{g}^{-1}$ ) and HKUST-1 (1500 mg $\mathrm{m}_{2} \mathrm{~g}^{-1}$ ) at fuel reprocessing conditions, with $10 \mathrm{wt} \% \mathrm{Ag} \&$ two lowsintering glass powders (EG2922 \& EG2998). The pellets were prepared using $2.5 \mathrm{~g}$ powder (10wt\% $\mathrm{I}_{2} @$ ZIF-8 or 10 wt $\% \mathrm{I}_{2} @$ HKUST-1, 10 wt $\%$ Ag, and 80\% low sintering glass) with uniaxial mechanical pressure of $70 \mathrm{MPa}$ in a steel die. The leach durability of the materials was studied using product consistency test (PCT) after heating pellets in $10 \mathrm{~mL}$ deionized water at $363 \mathrm{~K}$ for $7 \mathrm{~d}$. Specially, Bi-Zn-Si based glass (EG2922) amorphous showed higher chemical stability compared to crystalline glass (EG2998). It indicates that the GCMs are highly promising as waste forms for volatile gases (such as iodine) sequestered by surface area MOFs [93].

\subsubsection{Radioactive krypton and xenon}


MOFs such as IRMOF-1, HKUST-1 and AIMIL-53 have shown good potential for the separation of $\mathrm{Kr}$ and $\mathrm{Xe}$ from air. Possible MOFs structures number into hundreds of thousands, which warrants finding an efficient way to predict the most effective structures for the application of $\mathrm{Xe}$ and $\mathrm{Kr}$ adsorption. GCMC simulations have been the method of choice to computationally screen MOF structures for their adsorption properties, and many recent studies have reported upon this technique [94 - 98]. GCMC simulations may take into account geometric properties such as pore limiting diameters, largest cavity diameters, and accessible void volume [94]. Table 3 indicates the capacity of few MOFs for noble gases ( $\mathrm{Kr}$ and $\mathrm{Xe}$ ) using simulation.

Snurr and coworkers [94] reported on 137,000 hypothetical MOFs and separate high framework for Xe to $\mathrm{Kr}$ selectivity using GCMC simulations. The relation of MOFs pore structure to selectivity and capacity was found and it was shown that there is a tradeoff between selectivity and sorption capacity in MOFs. It was suggested that the MOF cavities would hold at least one Xe atom, which increased the selectivity of Xe. High volume calculations such as this one are quite insightful into the trend of adsorption with common structural characteristics. Using more applied simulations requires many input parameters and assumptions: Charge distributions, structure flexibility, atomic properties and Lennard Jones parameters. GCMC simulation was used to explore sorption behavior of $16 \mathrm{MOFs}$ for noble gases (krypton and argon) and nitrogen to identify key structural properties for selective sorption of noble gases from air. They concluded that more polarized and heavier gases are easier to separate from less polarized and lighter gases, nitrogen at low pressure (1 bar) [95].

Thallapally and coworkers [2, 99 - 104] developed several MOFs for same applications at nuclear reprocessing conditions. They studied the selectivity of $\mathrm{Kr} / \mathrm{Xe}$ separation as a function of temperature in two partially fluorinated MOFs (FMOFCu and FMOFZn). The $\mathrm{Kr} / \mathrm{Xe}$ selectivity of $\mathrm{FMOFCu}$ was 36 at $203 \mathrm{~K}$ and 0.1 bar [99]. At 
noncryogenic temperature (298 K) and 1 bar, MOF, NiDOBDC adsorb Xe (55 wt \%), which is a higher than that of the MOF-5, but, almost equal to uptake by activated carbon (coconut shell) [100]. In another study, adsorption isotherms of $\mathrm{Xe}, \mathrm{Kr}$ and $\mathrm{Xe} / \mathrm{Kr}$ from mixture of $\mathrm{N}_{2} / \mathrm{O}_{2} / \mathrm{Ar} / \mathrm{CO}_{2} / \mathrm{Xe} / \mathrm{Kr}$ gas stream were investigated by two well-known MOFs, HKUST-1 and $\mathrm{Ni} / \mathrm{DOBDC}$ and their results were compared with AC (coconut shell) using a dynamic breakthrough column at $298 \mathrm{~K}$ and 1 bar. The reasons for the selection of these this two MOFs were (a) high hydrothermal stability of Ni/DOBDC [101], and (b) both the MOFs contained unsaturated metal centers which are polar sites favorable for $\mathrm{Kr}$ and $\mathrm{Xe}$ sorption [94]. HKUST-1 and Ni/DOBDC have large pore diameter 15 and $11 \AA$, respectively. For both the MOFs, preferential sorption of Xe over $\mathrm{Kr}$ (capacities in $\mathrm{mol} \mathrm{kg}^{-1}$ : Ni/DOBDC 3.83 for Xe and 1.69 for $\mathrm{Kr}$, and HKUST-1 - 3.18 for Xe and 1.92 for $\mathrm{Kr}$ ) may be due to larger polarizability of $\mathrm{Xe}$ enhancing the interactions with polarizable adsorbents. $\mathrm{Ni} / \mathrm{DOBDC}$ had higher Xe sorption capacity than activated carbon $\left(3.72 \mathrm{~mol} \mathrm{~kg}{ }^{-1}\right)$. The capacity at 1000 ppm of Xe in air was found to be $9.3 \mathrm{mmol} \mathrm{kg}^{-1}$ [102]. The Ag@ MOF-74Ni MOFs adsorbed $63.2 \%$ mass of $\mathrm{Xe}$, which is $15.3 \%$ higher than original MOF-74Ni at room temperature and 1 bar. Kr sorption was not found to change significantly. A strong dipoleinduced dipole interactions between $\mathrm{Xe}$ and the well-dispersed $\mathrm{Ag}(\mathrm{I})$ cluster is the main reason for enhancement of Xe capacity on Ag@MOF-74Ni [103]. Two-column breakthrough experiments on two selected MOFs, Ni/DOBDC and FMOF-Cu, were conducted for capture and separation of ppm level of $\mathrm{Xe}$ and $\mathrm{Kr}$ from air at noncryogenic temperature. The results indicate that the FMOF-Cu has 3.7 times higher capacity than the Ni/DOBDC for krypton adsorption $\left(1.03 \mathrm{mmol} \mathrm{kg} \mathrm{g}^{-1}\right)$ in a two-column system. The two column technique is showing promising results for separation of Xe and $\mathrm{Kr}$ from air [104].

A few other research groups also focus on sorption and separation of $\mathrm{Kr}$ and $\mathrm{Xe}$ on MOFs. Forster and coworkers [105] studied two nonoporous transition metal formates, Co 
(II) formate $-\mathrm{Co}(\mathrm{HCOO})_{2} ; \mathrm{Ni}(\mathrm{II})$ formate $-\mathrm{Ni}(\mathrm{HCOO})_{2}$ as sorbents for pressure swing adsorption-based separation of $\mathrm{Kr}$ and $\mathrm{Xe}$. Their results indicated that metal formates were excellent sorbents for the separation of noble gases. Notably the higher heats of adsorption for xenon over krypton arise from the ability of xenon atoms to form dispersion interactions with large area of the pore surface. Magdysyuk et al. [106, 107] reported the structural investigation of $\mathrm{Kr}$ and $\mathrm{Xe}$ adsorption sites in different types of MOFs, CPO-27-Ni, CPO-27Mg and ZIF-8. They noticed that the noble gas adsorption occurred by two main factors of MOFs (1) channel morphology, and (2) polarizability of adsorption sites. The open metal sites are main and strong sorption sites for noble gases. Since the noble gases lack chemical reactivity, the only possible mechanism of adsorption for molecules was van der Waals interaction based on the polarizability of the atoms. Metal sites are the most polarizable part of the MOF's structure, and thus, these are the main adsorption sites with highest binding energy to adsorb noble gas atom. In another study, a large-pore MOF, $\mathrm{Cu}^{\mathrm{I}}-\mathrm{MFU}-4 l$ was developed with a large number of active site for $\mathrm{Xe}(10)$ and $\mathrm{Kr}(8)$ adsorption. The sorption of noble gas on MOFs formed a solid structure of intercalated atoms inside the cavities. This quasi-solid structure of $\mathrm{Kr}$ and $\mathrm{Xe}$ atoms in cavities formed by van der Waals interaction was stable above the boiling temperature of the corresponding gases. The binding energy in $\mathrm{Cu}^{\mathrm{I}}-$ MFU- $4 l$ enhanced the separation and storage capacity due to homogeneous adsorption of $\mathrm{Kr}$ and Xe.

As mentioned above, results of MOFs studies indicate that they are excellent media for the capture of radioactive iodine and capture/separation of $\mathrm{Kr}$ and $\mathrm{Xe}$ at reprocessing conditions. Specially, ZIF-8 and Cu-BTC with linked $\mathrm{Zn}$ and $\mathrm{Cu}$ atoms, respectively, have functioned well for the capture of radioactive iodine in laboratory experiments. However, the capacity of the MOFs depends on the number of iodine molecules linked with the $\mathrm{Zn}$ or $\mathrm{Cu}$ atoms. Similarly, $\mathrm{Kr} / \mathrm{Xe}$ separation are based on the polarity of the metal atom. As noted in 
these studies, metal sites are the most polarized parts of the MOF structure with high binding energy to adsorb noble gases. Increasing polarity enhances the separation of $\mathrm{Kr} / \mathrm{Xe}$ from the gas stream. The major limitation for the use of MOFs is cost effectiveness, with a large number of chemicals needed for their synthesis. Scaling up the synthesis for large scale manufacture may prove to be difficult for the MOF sorbents.

\section{Future trends and prospects}

The above review clearly indicates that porous solid sorbents are significant for the capture or removal of individual radioactive gases such as $\mathrm{I}_{2}$, $\mathrm{Xe}$ and $\mathrm{Kr}$ with a few limitations. However, several challenges need to addressed for further development of this technique before it can be implemented in practice. One of the major challenges is to resolve some of remaining questions with respect to deactivation of commercial sorbents with contaminants of interest. Reports on the multicomponent $\left(\mathrm{I}_{2}, \mathrm{Kr}, \mathrm{Xe}\right.$, air, water vapor) stream and competitive adsorption studies on adsorbents in continuous column experiments have been lacking in literature. Practically, off-gas streams contain a number of impurities such as NOx gases $\left(\mathrm{NO}, \mathrm{N}_{2} \mathrm{O}, \mathrm{NO}_{2}\right)$, carbon dioxide, nitric acid, and water vapor. Detailed investigations need to be conducted to examine the effect of operating temperature (25-150 ${ }^{\circ} \mathrm{C}$ ), effect of concentration of each contaminant, the inherent effect of each contaminant on sorbent, cycling of sorbent, and adverse effect of impurities on sorbent causing pore blockage, fouling, and ultimately reduced removal efficiency. Accurate mathematical models based on fundamental theory need to be developed to describe the mechanism of sorption, and validated from the experimental data.

\section{Conclusions}

Recent research progress on porous solid sorbents for the capture of radioactive gases has been thoroughly reviewed and presented in this paper. Wet processes such as Iodox and Mercurex, and cryogenic distillation, fluorocarbon absorption, membrane separation of $\mathrm{Kr} / \mathrm{Xe}$ 
are used for the removal of iodine and noble gases $(\mathrm{Kr}$ and $\mathrm{Xe})$ with large DFs. However, these techniques have several limitations for practical applications. The dry adsorption technique is comparatively better than the wet process for the capture of radioactive volatile gaseous. AC is one of the remarkable porous solid materials based on surface area and porosity of sorbent for capture of radionuclide contaminants of interest i.e. iodine, noble gases. However, this sorbent cannot be used for off-gas streams generated from used nuclear fuel reprocessing plant due to explosion hazards by $\mathrm{NO}_{\mathrm{x}}$. Silver-impregnated (zeolite or mordenite, silica, $\mathrm{Al}_{2} \mathrm{O}_{3}$ ) sorbents have great potential to capture iodine by chemical reaction with silver metal. Also, silver metal enhances the affinity of sorbent for capture or removal of noble gases due to electrostatic potential in helium carrier gas. Transition metal containing sorbents such as metal aerogels have potential for sorption applications, but these are cost prohibitive. ETS-10 supported carbon, C@ETS-10 was effective for capture of radioactive iodine and krypton at ambient temperate and pressure without any chemical reaction.

MOFs are very active for sorption of radioactive gases due to large surface area. ZIF8 shows excellent iodine sorption capacity due to large porosity of material (3.4 ̊). Grand Canonical Monte Carlo (GCMC) simulation has been used to check the activity of several MOFs for iodine, krypton and xenon adsorption. Ni/DOBDC represents the large Xe sorption capacity at room temperature and 1 bar due to larger polarizability of $\mathrm{Xe}$ enhancing the interactions with polarizable adsorbents. It has been shown that the porous solid sorbents are effective for capture or sorption of radioactive gases, which control the environmental pollution from growing nuclear power plants. The systematic study of solid sorbents in continuous column to reduce emissions of radioactive gaseous species (i.e. iodine, krypton and xenon) from the off-gas stream would contribute to maintaining pollution free/healthy environment, facilitating the growth of nuclear energy.

\section{Acknowledgment}


We would like to thank the US Department of Energy - Nuclear Energy University Program (DOE-NEUP) for financial support of this work (Project No.: DE-NE0000660).

\section{References}

[1] International energy outlook, U.S. energy information administration, Washington, DC, 2013.

[2] D. Banerjee, A. J. Cairns, J. Liu, R. K. Motkuri, S. K. Nune, C. A. Fernandez, R. Krishna, D. M. Strachan, P. K. Thallapally, Potential of metal-organic frameworks for separation of xenon and krypton, Acc. Chem. Res. 48 (2015) 211-219.

[3] Blue Ribbon commission on America's energy future report to the secretary of energy, U.S. Department of Energy, Washington DC, 2012.

[4] Key world energy statistics 2014, International Energy Agency (IEA), 2014.

[5] M. Kampa, E. Castanas, Human health effects of air pollution, Environ. Pollut. 151 (2008) 362 - 367.

[6] A. Markandya, P. Wilkinson, Electricity generation and health, Lancet 370 (2007) 979-90.

[7] Nuclear energy in a sustainable development perspective, OECD Nuclear Energy Agency, 2000.

[8] WNA, IAEA, Nuclear Engineering International, June 2014, http://worldnuclear.org/information-library/current-and-future-generation/nuclear-power-in-theworld-today.aspx.

[9] IAEA Annual Report 2012, http://nei.org/News-Media/News/News-Archives/IAEAProjects-up-to-100-Growth-of-Nuclear-Energy-b.

[10] Strategy for the management and disposal of used nuclear fuel and high-level radioactive waste, U.S. Department of Energy, Washington DC, 2013. 
[11] J. P. Nichols, F. T. Binord, Status of noble gas removal and disposal, Oak Ridge National Laboratory Report, ORNL-TM-3515, 1971.

[12] T. Fukasawa, K. Funabashi, Y. Kondo, Separation technology for radioactive iodine from off-gas streams of the nuclear facilities, J. Nucl. Sci. Technol. 31 (1994) 10731083.

[13] D. F. Sava, M. A. Rodriguez, K. W. Chapman, P. J. Chupas, J. A. Greathouse, P. S. Crozier, T. M. Nenoff, Capture of volatile iodine, a gaseous fission product, by zeolitic imidazolate framework-8, J. Am. Chem. Soc. 133 (2011) 12398-12401.

[14] P. Paviet-Hartmann, W. Kerlin, S. Bakhtiar, Treatment of gaseous effluents issued from recycling - A review of the current practices and prospective improvements, $11^{\text {th }}$ Actinide and fission products partitioning and transmutation exchange meeting, INL/CON-10-19961, Idaho National Laboratory, November 2010.

[15] L.L. Burger, R. E. Burns, Technical requirements for the control of ${ }^{129} \mathrm{I}$ in a nuclear fuels reprocessing plant, PNL - 3186, UC-70, Pacific Northwest Laboratory Richland, Washington, November 1979.

[16] D. R. Haefner, T. J. Tranter, Methods of gas phase capture of iodine from fuel reprocessing off-gas: A literature survey, INL/EXT-07-12299, Idaho National laboratory, February 2007.

[17] H. A. C. McKay, P. Miquel, I. F. White, Management modes for iodine-129, in Radioactive waste management, Management modes for iodine - 129, ed. W. Hebel and G. Cottone, Harwood Academic Publishers, vol. 7, 1982.

[18] N. Soelberg, T. Watson, Deep bed iodine sorbent testing FY 2011 report, INL/EXT11-23191, Idaho National Laboratory, Idaho Fall, 2011. 
[19] T. M. Nenoff, M. A. Rodriguez, N. R. Soelberg, K. W. Chapman, Silver-mordenite for radiologic gas capture from complex streams: Dual catalytic $\mathrm{CH}_{3} \mathrm{I}$ decomposition and I confinement, Microporous Mesoporous Mater. 200 (2014) 297-303.

[20] J. A. Dean, ed. Lange's handbook of chemistry, $15^{\text {th }}$ ed. McGraw Hill.

[21] L. E. Trevorrow, G. F. Vandegrift, V. M. Kolba, M. J. Steindler, Compatibility of technologies with regulations in the waste management of $\mathrm{H}-3, \mathrm{I}-129, \mathrm{C}-14$, and $\mathrm{Kr}$ 85. Part I. Initial information base, ANL-83-57, Argonne National Laboratory, Argonne, 1983.

[22] D. W. Holladay, A literature survey: methods doe the removal of iodine species from off-gases and liquid waste streams of nuclear power and nuclear fuel reprocessing plants, with emphasis on solid sorbents, ORNL/TM-6350, Oak Ridge National Laboratory, Oak Ridge, 1979.

[23] R. T. Jubin, A literature survey of methods to remove iodine from off-gas stream using solid sorbents, ORNL/TM-6607, Oak Ridge National Laboratory, 1979.

[24] M. J. Staphenson, R. S. Eby, Development of the Faster process for removing Krypton-85, carbon-14, and other contaminants from the off-gas of fuel reprocessing plants, Processing of the $14^{\text {th }}$ ERDA Air Cleaning, CONF -760822 , vol. 2, Sun Valley, ID, 1976.

[25] B. L. Vondra, LWR Fuel reprocessing and cycle processing quarterly report for period, ORNL/TM-5547, Oak Ridge National Laboratory, 1976.

[26] R. T. Jubin, Airborne waste management technology applicable for use in reprocessing plants for control of iodine and other off-gas constituents, ORNL/TM10477, Oak Ridge National Laboratory, 1988. 
[27] N. R. Soelberg, T. G. Garn, M. R. Greenhalgh, J. D. Law, R. Jubin, D. M. Strachan, P. K. Thallapally, Radioactive Iodine and Krypton Control for Nuclear Fuel Reprocessing Facilities, Sci. Technol. Nucl. Install. (2013) No. 7024961-12.

[28] Methods for removal of radionuclides from reprocessing plant gaseous streams, IAEA Bulletin, 21, 27-31.

[29] E. B. Moore, Control technology for radioactive emissions to the atmosphere at US Department of Energy facilities, PNL-4621-Final, Pacific Northwest Laboratory, Richland, WA, USA, 1984.

[30] J. R. Martln, G. Island, Radioactive krypton gas separation, US Pat 3944 646, 1976.

[31] P. R. Monson Jr., Krypton retention on solid adsorbents, DP-1615, UC-70, 1982.

[32] P. R. Monson, E. I. Du Pont De Nemours, Noble gas confinement for reactor fuel melting accidents, Proceedings of the $18^{\text {th }}$ DOE nuclear airborne waste management and air cleaning conference, CONF-840806, vol. 1, Baltimore, Maryland, 1984.

[33] S. A. Stern, S.-C. Wang, Permeation cascades for the separation of krypton and xenon from nuclear reactor atmospheres, AIChE J. 26 (1980) 891-901.

[34] K. Munakata, S. Kanjo, S. Yamatsuki, A. Koga, D. Ianovski, Adsorption of noble gases on silver-mordenite, J. Nucl. Sci. Technol. 40 (2003) 695-697.

[35] G. II Park, B. S. Choi, II H. Cho, J. H. Kim, Adsorption and desorption characteristics of methyl iodide on silver ion-exchanged synthetic zeolite at high temperature, J. Korean Nucl. Soc. 32 (2000) 504-513.

[36] G. II Park, I. Kim, J. K. Lee, S. K. Ryu, J. H. Kim, Effect of temperature on the adsorption and desorption characteristics of methyl iodide over TEDA-impregnated activated carbon, Carbon science 2 (2001) 9-14.

[37] H. Deuber, Investigation of the retention of elemental radioiodine by activated carbon at high temperature, Nucl. Technol. 72 (1986) 44-48. 
[38] C.-C. Chien, Y.-P. Huang, W.-C. Wang, J.-H. Chao, Y.-Y. Wei, Efficiency of moso bamboo charcoal and activated carbon for adsorbing radioactive iodine, Clean - Soil, Air, Water 39 (2011) 103-108.

[39] C. G. Doll, C. M. Sorensen, T. W. Bowyer, J. I. Friese, J. C. Hayes, E. Hoffmann, R. Kephart, Abatement of xenon and iodine emissions from medical isotope production facilities, J. Environ. Radioact. 130 (2014) 33-43.

[40] C. M. Gonzalez-Garcia, J. F. Gonzalez, S. Roman, Removal efficiency of radioactive methyl iodine on TEDA-impregnated activated carbons, Fuel Process. Technol. 92 (2011) 247-252.

[41] G. O. Wood, C. A. Kasunic, Methyl iodide retention on charcoal sorbents at parts-permillion concentration, Proceedings of the $15^{\text {th }}$ DOE Nuclear air cleaning conference, CONF - 780819, UC-70, Boston, Massachusetts, 1978.

[42] A. K. Srivastava, A. Saxena, B. Singh, S. K. Srivas, Development and evaluation of impregnated carbon systems against iodine vapours, Carbon Lett. 8 (2007) 274-279.

[43] H. Sun, P. La, Z, Zhu, W. Liang, B. Yang, A. Li, Capture and reversible storage of volatile iodine by carbon with high capacity, J. Mater. Sci. 50 (2015) 7326-7332.

[44] J. G. Wilhelm, J. Furrer, CEC seminar on radioactive effluents from nuclear fuel reprocessing plant, Karlsruhe, Germany, 1977.

[45] T. Fukasawa, K. Funabashi, Y. Kondo, Influences of impurities on iodine removal efficiency of silver alumina adsorbent, Proceedings of the $24^{\text {th }}$ DOE/NRC Nuclear Air Cleaning and Treatment Conference, 1996.

[46] T. Sakurai, A. Takahashi, M. Ye, T. Kihara, S. Fujine, Trapping and measuring radioactive (iodine - 129) in cartridge filters, J. Nucl. Sci. Technol. 34 (1997) 211216. 
[47] H. Mineo, M. Gotoh, M. Iizuka, S. Fujisaki, G. Uchiyama, A simple model predicting iodine profile in a packed bed of silica-gel impregnated with silver nitrate, J. Nucl. Sci. Technol. 39 (2002) 241-247.

[48] H. Mineo, M. Gotoh, M. Iizuka, S. Fujisaki, H. Hagiya, G. Uchiyama, Applicability of a model predicting iodine-129 profile in a silver nitrate silica gel column for dissolver off-gas treatment of fuel reprocessing, Sep. Sci. Technol. 38 (2003) 19812001.

[49] Q. Cheng, Z. Li, T. Chu, Adsorption of gaseous iodine-131 at high temperatures by silver impregnated alumina, Nucl. Sci. Technol. 26 (2015) 040303.

[50] D. T. Pence, F. A. Duce, W. J. Maeck, Application of metal zeolites to nuclear fuel reprocessing plant off-gas treatment, Trans. ANS 15 (1972) 96.

[51] N. Soelberg, T. Watson, Iodine sorbent performance in FY 2012 deep bed tests, INL/EXT-12-27075, Idaho National Laboratory, Idaho Fall, 2012.

[52] K. K. Patton, S. H. Bruffey, R. T. Jubin Jr., J. F. Walker, Iodine Loading of NO aged silver exchanged modernite, Fuel Cycle Research and development, FCRD-SWF2014-000277, ORNL/LTR-2014/425, Oak Ridge National Laboratory, Oak Ridge, 2014.

[53] R. T. Jubin, D. W. Ramey, B. B. Spencer, K. K. Anderson, S. M. Robinson, Impact of pretreatment and aging on the iodine capture performance of silver exchanged modenite, Waste Management, Phoenix, AZ, 2012.

[54] K. W. Chapman, P. J. Chupas, T. M. Nenoff, Radioactive iodine capture in silvercontaining mordernites through nanoscale silver iodide formation, J. Am. Chem. Soc. $132(2010) 8897-8899$. 
[55] L. Wu, J. A. Sawada, D. B. Kuznicki, T. Kuznicki, S. M. Kuznicki, Iodine adsorption on silver-exchanged titania-derived adsorbents, J. Radioanal Nucl Chem. 302 (2014) $527-532$.

[56] R. D Scheele, C. F Wend, Solidification and stabilization of silver mordenite used to control radioiodine emissions from Hanford's Waste Treatment Plant, Ann. Nucl. Energy 78 (2015) 40-48.

[57] T. J. Garino, T. M. Nenoff, J. L. Krumhansl, D. X. Rademacher, Low-Temperature sintering $\mathrm{Bi}-\mathrm{Si}-\mathrm{Zn}-\mathrm{Oxide}$ glasses for use in either glass composite materials or core/shell ${ }^{129}$ I waste forms, J. Am. Ceram. Soc. 94 (2011) 2412-2419.

[58] A. Soleimani Dorcheh, M. H. Abbasi, Silica aerogel; synthesis, properties and characterization, J. Mater. Process. Technol. 199 (2008) 10-26.

[59] S. M. Scott, T. Hu, T. Yao, G. Xin, J. Lian, Graphene-based sorbents for iodine-129 capture and sequestration, Carbon 90 (2015) 1-8.

[60] B. J. Riley, J. Chun, J. V. Ryan, J. Matyas, X. S. Li, D. W. Matson, S. K. Sundaram, D. M. Strachan, J. D. Vienna, Chalcogen-based aerogels as a multifunctional platform for remediation of radioactive iodine, RSC Adv. 1 (2011) 1704-1715.

[61] B. J. Riley, J. Chun, W. Um, W. C. Lepry, J. Matyas, M. J. Olszta, X. Li, K. Polychronopoulou, M. G. Kanatzidis, Chalcogen-based aerogels as sorbents for radionuclide remediation, Environ. Sci. Technol. 47 (2013) 7540-7547.

[62] B. J. Riley, D. A. Pierce, J. Chun, J. Matyas, W. C. Lepry, T. G. Garn, J. D. Law, M. G. Kanatzidis, Polyacrylonitrile-Chalcogel hybride sorbents for radioiodine capture, Environ. Sci. Technol. 48 (2014) 5832-5839.

[63] K. S. Subrahmanyam, D. Sarma, C. D. Malliakas, K. Polychronopoulou, B. J. Riley, D. A. Pierce, J. Chun, M. G. Kanatzidis, Chalcogenide aerogels as sorbents for radioactive iodine, Chem. Mater. 27 (2015) 2619-2626. 
[64] J. H. Yang, J. M. Shin, J. J. Park, G. II. Park, M. S. Yim, Novel synthesis of bismuthbased adsorbents for the removal of ${ }^{129}$ I in off-gas, J. Nucl. Mater. 457 (2015) 1-8.

[65] J. H. Yang, Y.-J. Cho, J. M. Shin, M.-S. Yim, Bismuth-embedded SBA-15 mesoporous silica for radioactive iodine capture and stable storage, J. Nucl. Mater. 465 (2015) 556-564.

[66] M. Outokesh, A. Saket, S. J. Ahmadi, M. Hosseinpour, A. R. Khanchi, Comparative study on adsorption of iodine vapor by silica-supported $\mathrm{Cu}$ nanoparticles and micronized copper, Ind. Eng. Chem. Res. 51 (2012) 15315-15323.

[67] S. U. Nandanwar, K. Coldsnow, M. Green, V. Utgikar, P. Sabharwall, D E. Aston, Activity of nanostructured C@ETS-10 sorbent for capture of volatile radioactive iodine from gas stream, Chem. Eng. J. 287 (2016) 593-601.

[68] S. U. Nandanwar, J. Dantas, K. Coldsnow, M. Green, V. Utgikar, P. Sabharwall, D. E. Aston, Porous microsphere of magnesium oxide as an effective sorbent for removal of volatile iodine from off-gas stream, Adsorption 22 (2016) 335-345.

[69] S. V. Potapov, A. A. Fomkin, V. A. Sinitsyn, A. V. Shkolin, Krypton adsorption on microporous adsorbents at higher pressures, Prot. Met. Phys. Chem. Surf. 46 (2010) 639-643.

[70] D. Ianovski, K. Munakata, S. Kanjo, Y. Yokoyama, A. Koga, S. Yamatsuki, K. Tanaka, T. Fukumatsu, M. Nishikawa, Y. Igarashi, Adsorption of noble gases on HMordenite, J. Nucl. Sci. Technol. 39 (2002) 1213-1218.

[71] S. Kitani, J. Takada, Adsorption of krypton and xenon on various adsorbents, J. Nucl. Sci. Technol. 2 (1964) 51-56.

[72] K. Munakata, T. Fukumatsu, S. Yamatsuki, K. Tanaka, M. Nishikawa, Adsorption equilibria of krypton, xenon, nitrogen and their mixtures on molecular sieve 5A and activated charcoal, J. Nucl. Sci. Technol. 36 (1999) 818-829. 
[73] K. Munakata, T. Shinozaki, H. Okabe, Adsorption of krypton on adsorbents at cryogenic temperatures, J. Power Energy Sys. 2 (2008) 171-177.

[74] M. Muris, N. Dufau, M. Bienfait, N. Dupont-Pavlovsky, Y. Grillet, J. P. Palmari, Methane and krypton adsorption on single-walled carbon nanotubes, Langmuir 16 (2000) 7019-7022.

[75] S. Jalili, R. Majidi, Study of $\mathrm{Xe}$ and $\mathrm{Kr}$ adsorption on open single-walled carbon nanotubes using molecular dynamics simulations, Physica E 39 (2007) 166-170.

[76] D. M. Strachan, P. K. Thallapally, S. A. Bryan, R. D. Scheele, C. H. Henager, W. J. Weber, T. G. Levitskaia, F. Zheng, J. Matyas, Processes for Removal and Immobilization of ${ }^{14} \mathrm{C},{ }^{129} \mathrm{I}$, and ${ }^{85} \mathrm{Kr}$, Pacific Northwest National Laboratory, Richland, WA, 2009.

[77] T. Garn, M. Greenhalgh, J. Law, Novel sorbent development and evaluation for the capture of krypton and xenon from nuclear fuel reprocessing off-gas streams, INL/CON-13-29010, Idaho National Laboratory, Idaho Fall, 2013.

[78] C. Daniel, A. Elbaraoui, S. Aguado, M-A. Springuel-Huet, A. Nossov, J-P. Fontaine, S. Topin, T. Taffary, L. Deliere, Y. Schuurman, D. Farrusseng, Xenon capture on silver-loaded zeolites: characterization of very strong adsorption sites, J. Phys. Chem. C 117 (2013) 15122-15129.

[79] K. Munakata, S. Yamatsuki, K. Tanaka, T. Fukumatsu, Screening test of adsorbents for recovery of krypton, J. Nucl. Sci. Technol. 37 (2000) 84-89.

[80] S.M. Kuznicki, A. Anson, A. Koenig, T. M. Kuznicki, T. Haastrup, Xenon adsorption on modified ETS-10, J. Phys. Chem. C 111 (2007) 1560-1562.

[81] S. U. Nandanwar, K. Coldsnow, V. Utgikar, P. Sabharwall, D. E. Aston, Y. Zhang, Synthesis and characterization of ETS-10: supported hollow carbon nano-polyhedrons 
nanosorbent for adsorption of krypton at near ambient temperatures, Adsorption 22 (2016) $129-137$.

[82] C. Jameson, A. Jameson, H-M Lim, Competitive adsorption of xenon and krypton in zeolite NaA: 129Xe nuclearmagnetic resonance studies and grand canonical Monte Carlo simulations, J. Chem. Phys. 107 (1997) 4364-4372.

[83] M. A. Nasalevich, M. van der Veen, F. Kapteijn, J. Gascon, Metal-organic frameworks as heterogeneous photocatalysts: advantages and challenges, CrystEngComm. 16 (2014) 4919-4926.

[84] B. Zornoza, C. Tellez, J. Coronas, J. Gascon, F. Kapteijn, Metal organic framework based mixed matrix membranes: An increasingly important field of research with a large application potential, Microporous Mesoporous Mater. 166 (2013) 67-78.

[85] T. Rodenas, M. van Dalen, P. Serra-Crespo, F. Kapteijn, J. Gascon, Mixed matrix membranes based on $\mathrm{NH}_{2}$-functionalized MIL-type MOFs: Influence of structural and operational parameters on the $\mathrm{CO}_{2} / \mathrm{CH}_{4}$ separation performance, Microporous Mesoporous Mater. 192 (2014) 35-42.

[86] G. Zhang, M. Mastalerz, Organic cage compounds - from shape-persistency to function, Chem. Soc. Rev. 43 (2014) 1934 - 1947.

[87] D. F. Sava, K. W. Chapman, M. A. Rodriguez, J. A. Greathouse, P. S. Crozier, H. Zhao, P. J. Chupas, T. M. Nenoff, Competitive $\mathrm{I}_{2}$ sorption by $\mathrm{Cu}-\mathrm{BTC}$ from humid gas streams, Chem. Mater. 25 (2013) 2591-2596.

[88] K. W. Chapman, D. F. Sava, G. J. Halder, P. J. Chupas, T. M. Nenoff, Trapping guests within a nanoporous metal-organic framework through pressure-induced amorphization, J. Am. Chem. Soc. 133 (2011) 18583-18585. 
[89] T. D. Bennett, P. Simoncic, S. A. Moggach, F. Gozzo, P. Macchi, D. A. Keen, J. C. Tan, A.K. Cheetham, Reversible pressure-induced amorphization of a zeolitic imidazolate framework (ZIF-4), Chem. Commun. 47 (2011) 7983 - 7985.

[90] T. D. Bennett, P.J. Saines, D.A. Keen, J-C. Tan, A. K. Cheetham, Ball-MillingInduced amorphization of zeolitic imidazolate frameworks (ZIFs) for the irreversible trapping of iodine, Chem. Eur. J. 19 (2013) 7049 - 7055.

[91] J. T. Hughes, D. F. Sava, T. M. Nenoff, A. Navrotsky, Thermochemical evidence for strong iodine chemisorption by ZIF-8, J. Am. Chem. Soc. 135 (2013) 16256-16259.

[92] B. Assfour, T. Assaad, A. Odeh, In silico screening of metal organic framework for iodine capture and storage, Chem. Phys. Lett. 610-611 (2014) 45-49.

[93] D. F. Sava, T. J. Garino, T. M. Nenoff, Iodine confinement into metal-organic frameworks (MOFs): Low-temperature sintering glasses to form novel glass composite material (GCM) alternative waste forms, Ind. Eng. Chem. Res. 51 (2012) 614-620.

[94] B. J. Sikora, C. E. Wilmer, M. L. Greenfield, R. Q. Snurr, Thermodynamic analysis of $\mathrm{Xe} / \mathrm{Kr}$ selectivity in over 137,000 hypothetical metal-organic frameworks, Chem. Sci. 3 (2012) 2217-2223.

[95] M. Parkes, C. L. Staiger, J. J. Perry IV, M. D. Allendorf, J. A. Greathouse, Screening metal-organic frameworks for selective noble gas adsorption in air: effect of pore size and framework topology, Phys. Chem. Chem. Phys. 15 (2013) 9093-9106.

[96] P. Ryan, O. Farha, L. Snurr, R. Snurr, Computational screening of metal-organic frameworks for Xenon/Krypton separation, AIChE J. 57 (2011) 1759-1766.

[97] Z. Hulvey, K. V. Lawler, Z Qiao, J. Zhou, D. Fairen-Jimenez, R. Q. Snurr, S. V. Ushakov, A. Navrotsky, C. M. Brown, Noble gas adsorption in copper trimesate, 
HKUST-1: An experimental and computational study, J. Phys. Chem. C 117 (2013) 20116-20126.

[98] J. J. Perry IV, S. L. Teich-McGoldrick, S. T. Meek, J. A. Greathouse, M. Haranczyk, M. D. Allendorf, Noble gas adsorption in metal-organic frameworks containing open metal sites, J. Phys. Chem. C 118 (2014) 11685-11698.

[99] C. A. Fernandez, J. Liu, P. K. Thallapally, D. M. Strachan, Switching Kr/Xe selectivity with temperature in a metal-organic framework, J. Am. Chem. Soc. 134 (2012) 9046-9049.

[100] P. K. Thallapally, J. W. Grate, R. K. Motkuri, Facile xenon capture and release at room temperature using a metal-organic framework: a comparison with activated charcoal, Chem. Commun. 48 (2012) 347-349.

[101] J. Liu, J. Tian, P. K. Thallapally, B. P. McGrail, Selective $\mathrm{CO}_{2}$ capture from flue gas using Metal-Organic Frameworks-A fixed bed study, J. Phys. Chem. C 116 (2012) 9575-9581.

[102] J. Liu, P. K. Thallapally, D. Strachan, Metal-organic frameworks for removal of Xe and $\mathrm{Kr}$ from nuclear fuel reprocessing plants, Langmuir 28 (2012) 11584-11589.

[103] J. Liu, D. M. Strachan, P. K. Thallapally, Enhanced noble gas adsorption in Ag@MOF-74Ni, Chem. Commun. 50 (2014) 466-468.

[104] J. Liu, C. A. Fernandez, P. F. Martin, P. K. Thallapally, D. M. Strachan, A twocolumn method for the separation of $\mathrm{Kr}$ and $\mathrm{Xe}$ from process off-gases, Ind. Eng. Chem. Res. 53 (2014) 12893-12899.

[105] K. V. Lawler, Z. Hulvey, P. M. Forster, Nanoporous metal formats for krypton/xenon separation, Chem. Commun. 49 (2013) 10959-10961.

[106] O. V. Magdysyuk, F. Adams, H.-P. Liermann, I. Spanopoulos, P. N. Trikalitis, M. Hirscher, R. E. Morris, M. J. Duncan, L. J. McCormick, R. E. Dinnerbier, 
Understanding the adsorption mechanism of noble gases $\mathrm{Kr}$ and $\mathrm{Xe}$ in $\mathrm{CPO}-27-\mathrm{Ni}$, CPO-27-Mg, and ZIF-8, Phys. Chem. Chem. Phys. 16 (2014) 23908-23914.

[107] O. V. Magdysyuk, D. Denysenko, I. Weinrauch, D. Volkmer, M. Hirscher, R. E. Dinnebier, Formation of a quasi-solid structure by intercalated noble gas atoms in pores of $\mathrm{Cu}^{\mathrm{I}}$-MFU-41 metal-organic framework, Chem. Commun. 51 (2015) 714-717.

\section{Figures caption}

Fig. 1 Block diagram of off-gas generation stages at nuclear power station. Adopted from ref [15].

Fig. 2 The mechanism of dual catalytic $\mathrm{CH}_{3} \mathrm{I}$ decomposition and I confinement reaction pathway over the $\mathrm{Ag}^{0}$-MOR zeolite, from ref. [19].

Fig. 3 (a) Effect of empty bed contact time on iodine adsorption (b) Linear fir for Langmuir model for iodine adsorption on 10 wt \% C@ETS-10 at 293 K. Adapted from ref. [67].

Fig. 4 Breakthrough curve for krypton adsorption at $10 \mathrm{wt} \%$ C@ETS-10 and AC at ambient temperature and pressure [81].

Fig. 5 Capture of $I_{2}$ molecule on Cu-BTC ( $\left.I_{2} @ \mathrm{Cu}-\mathrm{BTC}\right)$ (a) $\mathrm{I}_{2}$ sitting in the triangular window; (b) one $I_{2}$ molecule occupancy within the smallest cage; (c) $I_{2}$ in the fourring window; (d) snapshot of the $\mathrm{I}_{2}$ arrangement in the $11 \AA$ cage. Atom color scheme: fuchsia $=\mathrm{I}$, blue $=\mathrm{Cu}$, gray $=\mathrm{C}$, red $=\mathrm{O}$, and white $=\mathrm{H}$, from ref. [87].

\section{Tables Caption}

Table 1 List of different sorbents for capture/removal of volatile iodine from gas stream 
Table 2 Krypton capacities of various sorbents

Table 3 Krypton and xenon adsorption on MOFs 


\section{Table 1}

\begin{tabular}{|c|c|c|c|c|c|}
\hline Sorbent & $\begin{array}{l}S \\
\left(m^{2} g^{-1}\right)\end{array}$ & $\begin{array}{l}\text { Temp. } \\
(\mathrm{K})\end{array}$ & $\begin{array}{l}\text { CS }\left(\mathrm{mg} \mathrm{g}^{-1}\right) / \\
\% \text { Removal } \\
\text { efficiency }\end{array}$ & Compound & Ref. \\
\hline $\begin{array}{l}\text { Silver-impregnated alumina } \\
(\mathrm{Ag}-\mathrm{A})\end{array}$ & - & $\geq 373$ & 220 & $\mathrm{CH}_{3} \mathrm{I}$ & {$[12]$} \\
\hline Silver-Exchanged Zeolite (AgX) & 699 & 373 & 250 & $\mathrm{CH}_{3} \mathrm{I}$ & {$[35]$} \\
\hline Activated carbon (AC) & 1420 & $>323$ & 320 & $\mathrm{CH}_{3} \mathrm{I}$ & {$[35]$} \\
\hline Zeocarbon & 820 & $>323$ & 100 & $\mathrm{CH}_{3} \mathrm{I}$ & {$[35]$} \\
\hline Zeolite (NaX) & 799 & 373 & 100 & $\mathrm{CH}_{3} \mathrm{I}$ & {$[35]$} \\
\hline TEDA-Impregnated AC & 1275 & 303 & 470 & $\mathrm{CH}_{3} \mathrm{I}$ & {$[36]$} \\
\hline Bomboo charcoal and AC & $\begin{array}{l}400 \& \\
900\end{array}$ & - & $\sim 70 \% 1^{\text {st }}$ layer & ${ }^{131} \mathrm{I}_{2}$ & [38] \\
\hline TEDA-impregnated AC & 626 & - & $98.1 \%$ & $\mathrm{CH}_{3} \mathrm{I}$ & {$[40]$} \\
\hline Porous carbon (AC) & 1973 & 350 & 3.76 & $\mathrm{I}_{2}$ & {$[43]$} \\
\hline $\begin{array}{l}\text { Silver-impregnated Silica gel } \\
(\mathrm{Ag}-\mathrm{S})\end{array}$ & - & 423 & $\sim 75$ & ${ }^{129} \mathrm{I}_{2}$ & [46] \\
\hline Silver impregnated Alumina & 107 & 450 & 806F.9 DF & $\mathrm{I}_{2}$ & [49] \\
\hline$\left(\mathrm{Ag} / \mathrm{Al}_{2} \mathrm{O}_{3}\right)$ & & & Value & & \\
\hline Ag-ETS-10 \& & - & 353 & $17.1 \% \&$ & - & [55] \\
\hline Ag-ETS-2 & & & $24.3 \%$ & & \\
\hline $\begin{array}{l}\text { Chalcogen-based aerogels } \\
(\mathrm{Pt}-\mathrm{Ge}-\mathrm{S})\end{array}$ & 490 & $\begin{array}{l}298 \\
\sim 413\end{array}$ & $\begin{array}{l}240 \text { mass } \% \\
99 \% \text { removal }\end{array}$ & $\mathrm{I}_{2}$ & [60] \\
\hline
\end{tabular}


Table 1 (cont.)

Chalcogen-based Aerogels

456

398

$>99 \%$

$\mathrm{I}_{2}$

[61]

$(\mathrm{SnS})$

Polyacrylonitrile -Chalcogel

270

398

$>99.3 \%$

[62]

hybrid (PAN-SnS)

Bismuth-embedded SBA-15

368

473

540

$\mathrm{I}_{2}$

[65]

mesoporous silica

Silica-supported $\mathrm{Cu}$ nanoparticles 336

$493 \quad 95 \%$ \&

$\mathrm{I}_{2}$

[66]

and micronized copper

$51 \%$

C@ETS-10

149

293

40

$\mathrm{I}_{2}$

[67]

$\mathrm{MgO}$ nanostructured

83

298

196

$\mathrm{I}_{2}$

[68]

$S=$ BET surface area; Temp. $=$ Temperature; $C S=$ Capacity of sorbent 
Table 2

\begin{tabular}{llllll}
\hline Sorbents & Surface Area & Pressure & Capacity of sorbent & Temp. & Ref. \\
& $\left(\mathrm{m}^{2} \mathrm{~g}^{-1}\right)$ & $(\mathrm{Pa})$ & $\left(\mathrm{mol} \mathrm{g}^{-1}\right)$ & $(\mathrm{K})$ & \\
\hline Silver Mordenite & 109 & 15 & $2.30 \mathrm{E}-06$ & 273 & {$[34]$} \\
AUK microporous carbon & - & 2981 & $3.20 \mathrm{E}-03$ & 177.7 & {$[69]$} \\
AC & 663 & 20 & $1.10 \mathrm{E}-06$ & 273 & {$[70]$} \\
Natural mordenite & 217 & 25 & $6.50 \mathrm{E}-07$ & 273 & {$[70]$} \\
MS-5A & 415 & 30 & $2.70 \mathrm{E}-07$ & 273 & {$[70]$} \\
Ambersoeb 572 & 1100 & 30 & $2.20 \mathrm{E}-06$ & 273 & {$[70]$} \\
Ambersoeb 563 & - & 40 & $2.00 \mathrm{E}-06$ & 273 & {$[70]$} \\
Molsievon X2M4/6 & - & 20 & $1.70 \mathrm{E}-07$ & 273 & {$[70]$} \\
Molsievon 3A & - & 1000 & $2.00 \mathrm{E}-06$ & 273 & {$[70]$} \\
Merck & - & 10 & $5.00 \mathrm{E}-07$ & 273 & {$[70]$} \\
Cu-Mordenite & - & 20 & $3.50 \mathrm{E}-07$ & 273 & {$[70]$} \\
Hydrogen Mordenite $(\mathrm{HM})$ & 295 & 15 & $4.00 \mathrm{E}-05$ & 273 & {$[70]$} \\
SWCNT & 371.5 & $2.60 \mathrm{E}-03$ & & {$[74]$} \\
\hline
\end{tabular}


Table 3

\begin{tabular}{|c|c|c|c|c|c|c|c|}
\hline \multirow{2}{*}{ MOFs } & \multirow{2}{*}{$\begin{array}{l}\text { Surface Area } \\
\left(\mathrm{m}^{2} \mathrm{~g}^{-1}\right)\end{array}$} & \multirow{2}{*}{$\begin{array}{l}\text { Pressure } \\
(\mathrm{kPa})\end{array}$} & \multirow{2}{*}{$\begin{array}{l}C S_{K r} \\
\left(\mathrm{~mol} \mathrm{~kg}^{-1}\right)\end{array}$} & \multirow{2}{*}{$\begin{array}{l}C S_{X e} \\
\left(\mathrm{~mol} \mathrm{~kg}^{-1}\right)\end{array}$} & \multicolumn{3}{|c|}{ Temp } \\
\hline & & & & & $\mathrm{Se}_{\mathrm{X} e / \mathrm{K} r}$ & $(\mathrm{~K})$ & Ket. \\
\hline AIMIL-53 & 3231 & 600 & 2.6 & - & - & 308 & [95] \\
\hline ZIF-8 & 2851 & 600 & 1.1 & - & - & 308 & [95] \\
\hline PCN-14 & 3337 & 600 & 3.3 & - & & 308 & [95] \\
\hline IRMOF-1 & - & 100 & - & - & 3.7 & 273 & [96] \\
\hline HKUST-1 & 2770 & 100 & 1.3 & 4.9 & 8.1 & 273 & [96] \\
\hline MOF-505 & 3100 & 100 & - & - & 11.2 & 273 & [96] \\
\hline UMCM-1 & - & 100 & 0.8 & 2.5 & 3.6 & 273 & [96] \\
\hline NiDOBDC & - & 100 & 1.69 & 3.83 & 2.3 & 298 & [102] \\
\hline
\end{tabular}

$C S_{K r}$ - Capacity of sorbent for krypton; $C S_{X e}-$ Capacity of sorbent for xenon; $S e_{X e / K r}-$ Selectivity of $\mathrm{Xe} / \mathrm{Kr}$ 
Figures

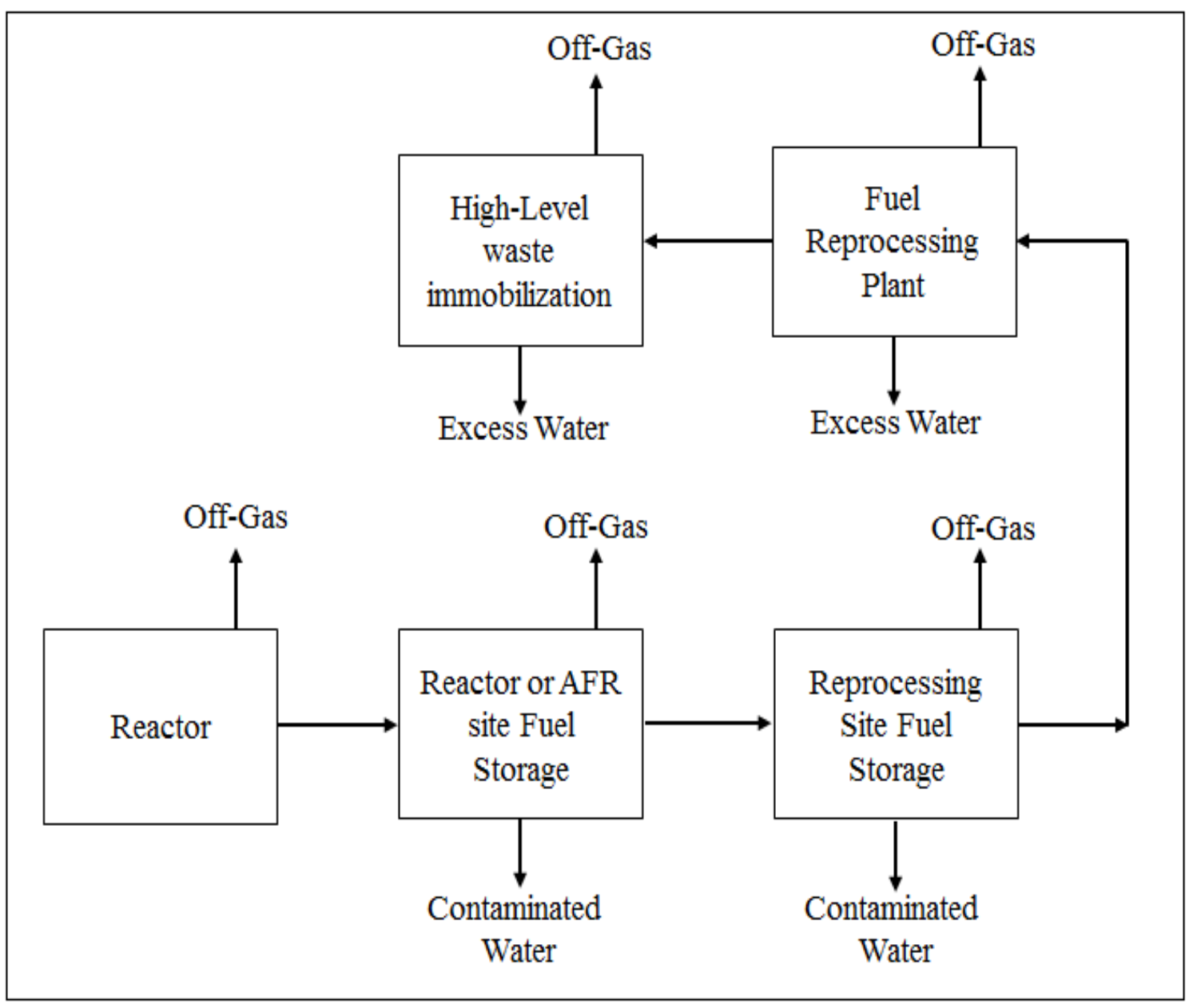

Fig. 1. 


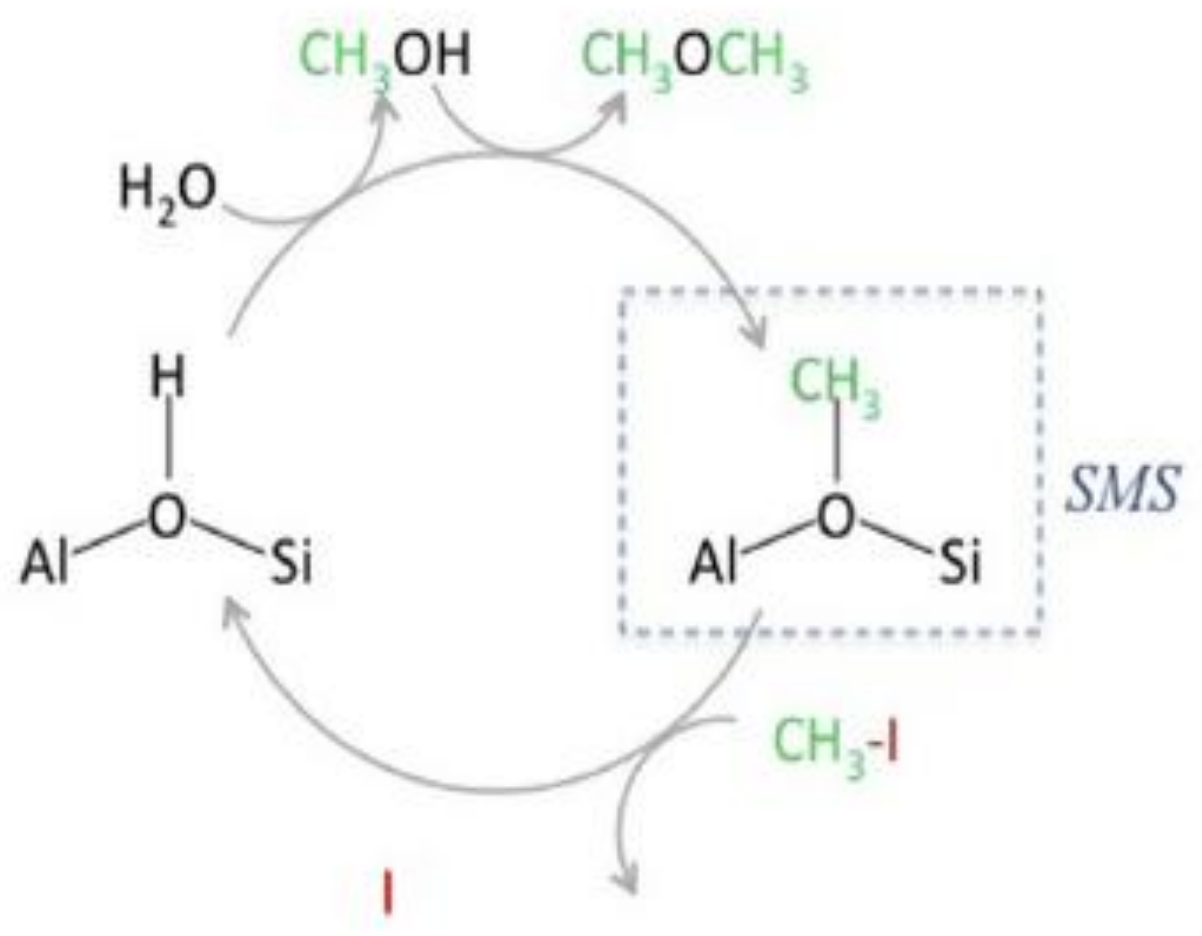

Fig. 2. 

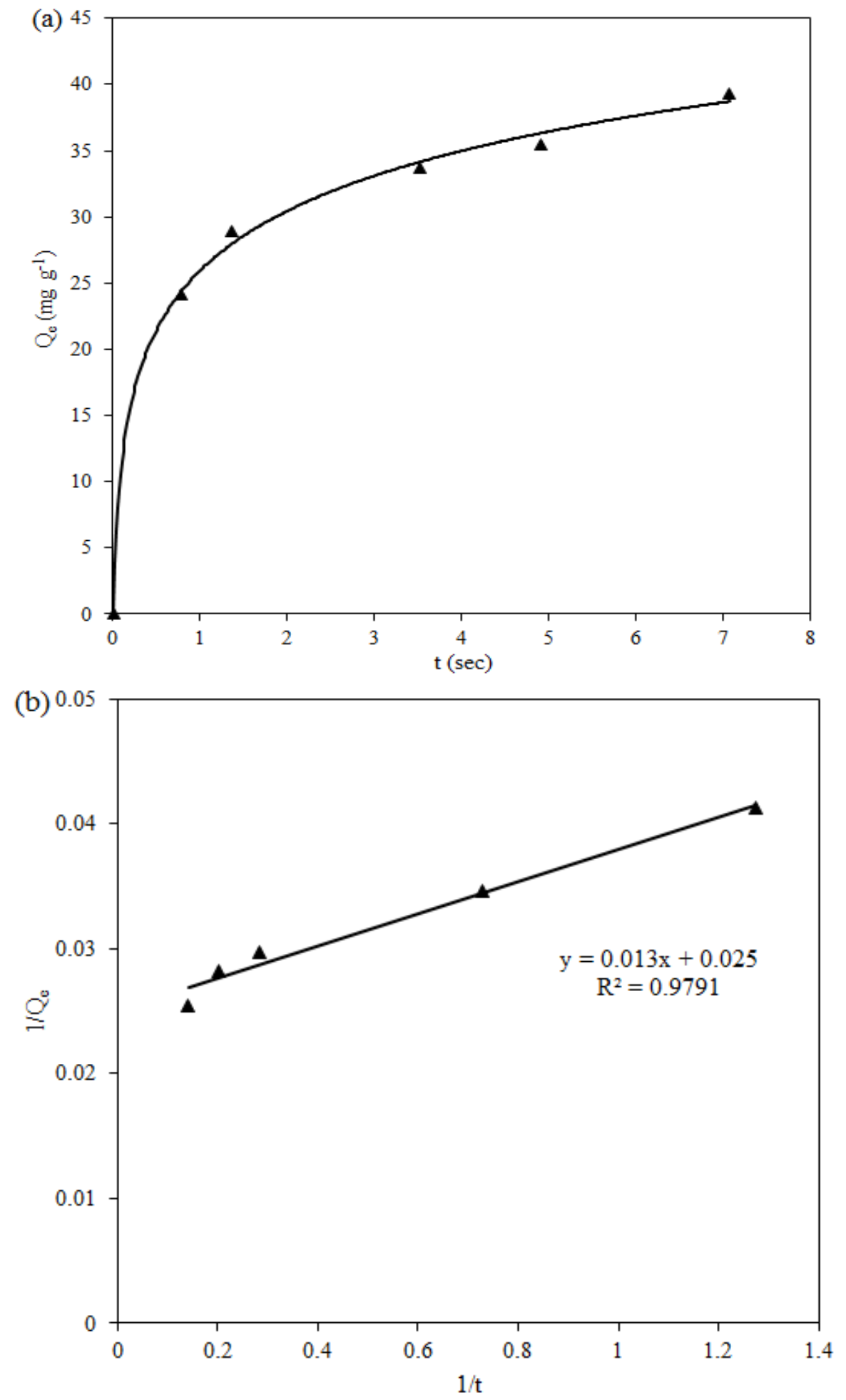

Fig. 3. 


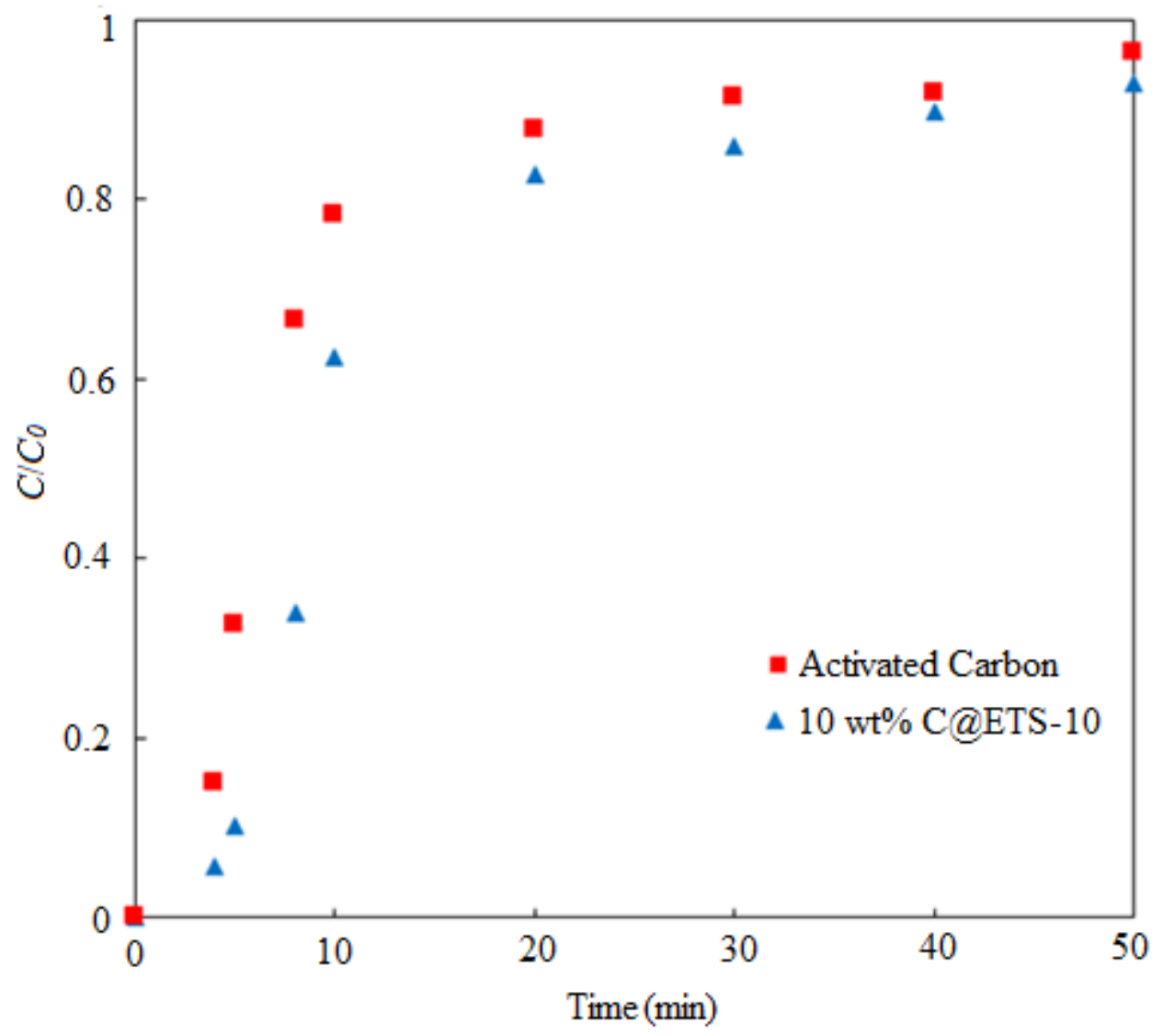

Fig. 4. 

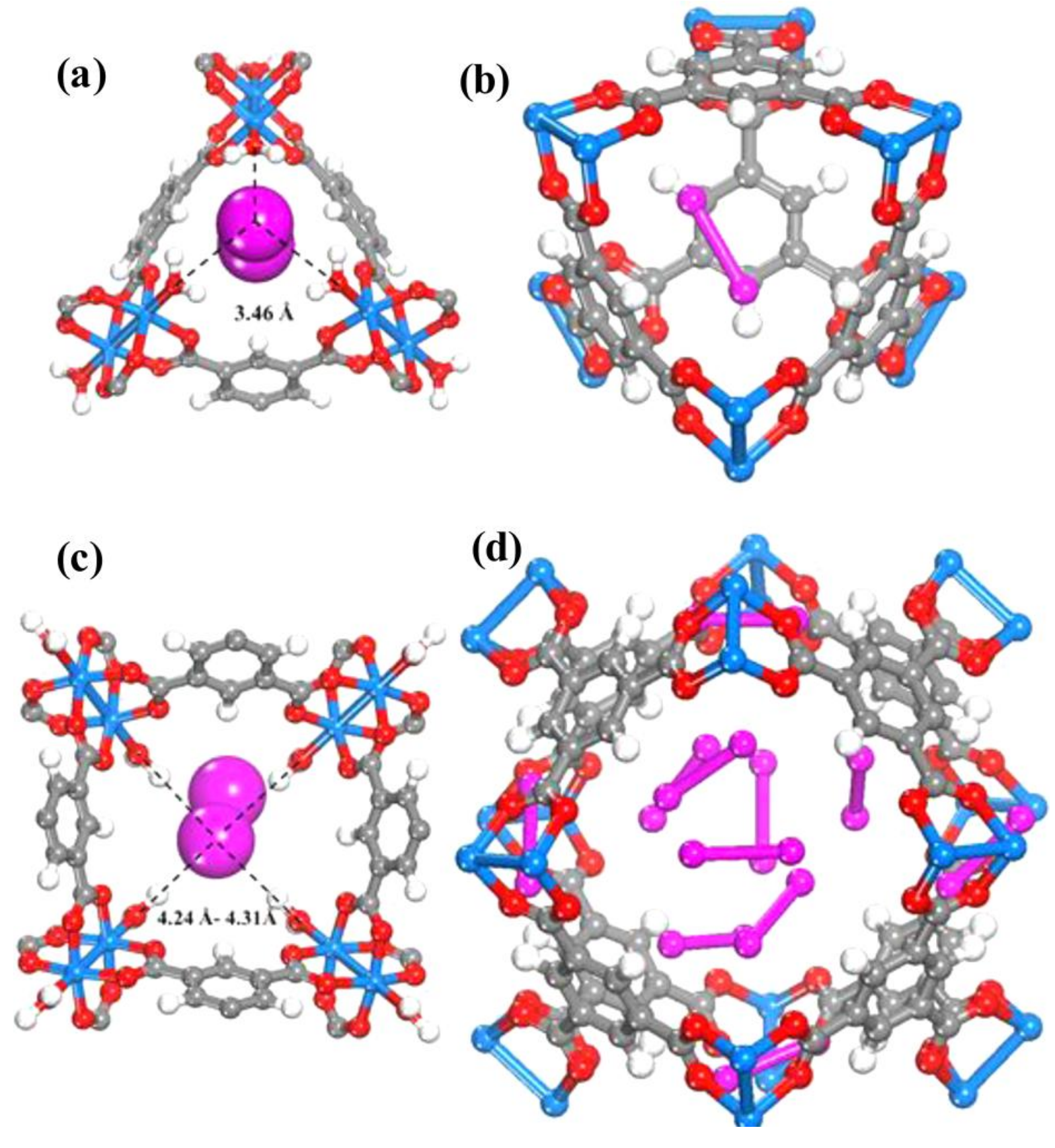

Fig. 5. 